\title{
ESTUDIOS
}

\section{Aportaciones al estudio del melólogo en España e Hispanoamérica: El negro sensible entre dos orillas y varios contextos 1}

\author{
Contributions to the study of melologue \\ in Spain and Hispanic America: El negro sensible \\ between two shores and several contexts
}

\author{
por \\ Virginia Sánchez López \\ Universidad de Jaén, España \\ vsanchez@ujaen.es
}

\begin{abstract}
El presente artículo aporta información desconocida y nuevas hipótesis acerca del cultivo del melólogo en el área hispánica, tomando como caso de estudio El negro sensible, melodrama escrito por el popular dramaturgo Luciano Comella y estrenado en Madrid en 1798. Al hecho de ser uno de los escasos melólogos de temática americana (trata sobre la esclavitud bajo el prisma de la nueva racionalidad ilustrada), se une su rápida llegada a la ciudad de México, donde se escenificó en 1805 y se escribió una segunda parte en 1825 por José Joaquín Fernández de Lizardi. Tras una breve introducción al género dramático-musical del melólogo, la primera sección del trabajo recoge informaciones dispersas respecto de las vicisitudes de El negro sensible en los coliseos públicos de Madrid y el Nuevo Mundo. La segunda parte se centra en la versión musical que Ramón Garay, maestro de capilla de la Catedral de Jaén, compuso para los marqueses del Cerro de la Cabeza, en un contexto productivo hasta ahora inexplorado para este tipo de teatro breve como era el ámbito privado de la nobleza. Con el propósito de realizar una aportación a la escueta lista de melólogos publicados en edición moderna, se ofrece una transcripción musical del melólogo de Garay. De esta manera, el trabajo subraya la necesidad de estudiar los procesos de intercambio entre ambas orillas y los cambiantes contextos dramatúrgicos de los géneros teatrales breves con música, en particular del melólogo.
\end{abstract}

Palabras clave: Melólogo (melodrama), teatro breve, música instrumental, esclavismo, España, Hispanoamérica, marqueses del Cerro de la Cabeza, Luciano Comella, Ramón Garay.

1 Este trabajo ha sido realizado durante una estancia de investigación en el CESEM-Centro de Estudos de Sociologia e Estética Musical-FCSH, Universidad Nova de Lisboa, en el marco del Programa de Estancias de Movilidad de la Universidad de Jaén. Una versión preliminar fue presentada en el Coloquio Internacional A diplomacia e a aristocracia como promotores da música e do teatro na Europa do Antigo Regime, organizado por el Divino Sospiro-Centro de Estudos Musicales Setencistas de Portugal en el Palacio Nacional de Queluz el 1 de julio, 2016. La presente investigación forma parte del Proyecto de I+D+i Musicología aplicada al concierto clásico en España (siglos XVIII-XXI). Aspectos históricos, productivos, interpretativos e ideológicos (Ministerio de Economía y Competitividad, Gobierno de España, HAR2014-53143-P). Agradezco a Francisco Juan Martínez, archivero diocesano de Jaén, sus facilidades para desarrollar esta investigación, y a Javier Marín y José Antonio Gutiérrez sus comentarios al texto.

Revista Musical Chilena, Año LXXIII, enero-junio, 2019, No 231, pp. 9-38 Fecha de recepción: 11-09-2016. Fecha de aceptación: 28-05-2017 
This article contributes unknown information and new hypothesis about the cultivation of the melologue in the Hispanic area, taking as case-study The sensitive black, melodrama written by the popular playwright Luciano Comella and released in Madrid in 1798. To the fact of being one of the scanty melologues of American subject (it deals with the slavery as seen by the new illustrated rationality), it joins its quick arrival to Mexico City, where it was performed in 1805 and José Joaquín Fernández de Lizardi wrote a second part in 1825. After a brief introduction to the music-dramatical genre of the melologue, the first section gathers dispersed information about the vicissitudes of The sensitive black in the public theatres of Madrid and the New World. The second part focuses on the musical setting that Ramón Garay, chapel master of Jaen Cathedral, composed for the marquesses of the Cerro de la Cabeza in a productive context till now unexplored for this short lyric-theatrical pieces such as the private sphere of nobility. With the intention of making a contribution to the succinct list of melologues available in modern edition, I offer a musical transcription of Garay's piece. Thus, the article underlies in the need to study the processes of exchange between both shores and the changing dramaturgical contexts of short theatrical genres with music, in particular of the melologue.

Keywords: Melologue (melodrama), short theatre, instrumental music, slavery, Spain, Hispanic America, marquesses of the Cerro de la Cabeza, Luciano Comella, Ramón Garay.

\section{INTRODUCCIÓN}

En 1928 José Subirá publicó un pionero ensayo en el que llamaba la atención respecto del melólogo, un novedoso género dramático-musical de influencia francesa cultivado intensamente en España en las postrimerías del siglo XVIII y las primeras décadas del siglo XIX ${ }^{2}$. Ya en ese artículo, así como en otras publicaciones y en particular en la monografía que dedicó al tema años después ${ }^{3}$, afloraban algunos de los aspectos que interesan a este trabajo: la existencia de melólogos ambientados en América y la práctica del género tanto en la red de teatros públicos como -en menor medida- en entornos domésticos ligados a la nobleza. Partiendo de estas premisas, este trabajo se centra en El negro sensible, un melólogo poco conocido escrito por Luciano Comella que reúne esas características: ambientado en un paradisíaco ingenio azucarero del Caribe, narra la desdichada historia del esclavo Catul a los ojos de los ideales universales de generosidad y sensibilidad típicamente iluministas. Estrenado en Madrid en 1798, siete años después se repuso en México, donde fue prohibido por la Inquisición a causa de su carácter subversivo; pese a ello, el melodrama siguió gozando de fama y José Joaquín Fernández de Lizardi escribió una segunda parte que publicó en 1825. Este tipo de obras se interpretaban también en veladas privadas de corte aristocrático, lo que queda atestiguado por la existencia de una versión musical compuesta por el maestro de capilla de la Catedral de Jaén Ramón Garay para los marqueses del Cerro de la Cabeza. Además de profundizar en la vida de esta tipología de teatro musical y analizar sus distintos contextos productivos en el área hispánica, aspectos que yo misma he desarrollado a propósito de otros géneros ${ }^{4}$, este trabajo propone la hipótesis de entender el melólogo como un artefacto cultural en circulación que refleja en ambas orillas los cambios de gusto y el nuevo sentimentalismo ilustrado de la clase media y las élites aristocráticas.

\footnotetext{
2 Subirá 1928: 140-161.

3 Subirá 1949-50.

4 Sánchez López 2012.
} 


\section{EL NEGRO SENSIBLE EN LOS CIRCUITOS TEATRALES: DE LAS TABLAS MADRILENAAS A LOS COLISEOS HISPANOAMERICANOS}

Basándose en las pioneras investigaciones de José Subirá, autor del estudio de referencia respecto de este género de compleja genealogía terminológica ${ }^{5}$, Eduardo Huertas ofrece una completa definición de melólogo:

Es un género de teatro musical, menor y mixto, en que se combinan, alternando, la palabra, el verso y la música orquestal; y en otros casos, también el gesto o la mímica y el canto coral. Dicha alternancia es, teatralmente hablando, estructural, ya que la música es la otra parte dialogante de la obra y, como tal, desarrolla, igual que el actor, la trama, subrayando y también expresando estado de ánimo ${ }^{6}$.

El inventor de esta fórmula fue Jean-Jacques Rousseau (1712-1778), quien se referirá a ella como "melodrama", aunque su Pygmalion, considerada la primera obra del género (1770), recibió la denominación de scène lyrique ${ }^{7}$. Su estreno madrileño tuvo lugar en 1788 en el Teatro de los Caños del Peral y ese mismo año ya se ejecutó en Cádiz la "escena lírica soliloquio unipersonal" Hanníbal de José Ignacio González del Castillo y música perdida de autor desconocido ${ }^{8}$. También será el coliseo gaditano el lugar donde se estrene, en 1790, la pieza que inaugura oficialmente la tradición melologuista en la península ibérica: Guzmán el Bueno, con texto y música de Tomás de Iriarte ${ }^{9}$. El éxito del melólogo de Iriarte en los teatros de Madrid a partir de 1791 hizo eclosionar el género, del que Subirá contabilizó sesenta y seis títulos a partir de su trabajo en archivos madrileños ${ }^{10}$. Esta cifra sin duda aumentaría si se computasen las traducciones de melólogos franceses y alemanes, así como las adaptaciones y nuevas creaciones en otros núcleos peninsulares y en ciudades hispanoamericanas, algo de lo que el propio musicólogo catalán ya era consciente ${ }^{11}$. La función principal de los números musicales era la de glosar y potenciar los sentimientos y estados de ánimo del protagonista sin mediación del lenguaje hablado, conformando una nueva categoría expresiva distinta a la del teatro lírico y a la del teatro declamado que otorga a la música instrumental una plena autonomía de significado ${ }^{12}$. Existió otra variante del melólogo cultivada en Alemania por Georg Benda (1722-1795), en la que la declamación se produce sobre la música y no en alternancia con ella, como proponía Rousseau, siendo una fórmula menos explorada por los creadores españoles. Subirá ofreció un completo

5 Subirá 1949-50. Entre los trabajos recientes de conjunto merecen destacarse, además de la entrada lexicográfica de Suárez-Pajares 2000, los de Álvarez Barrientos 2005, Palacios Fernández 2008: 578-582 y Jones 2012. Sobre la cuestión terminológica, ver el clarificador ensayo de Guijarro Ceballos 2011: 39-52.

6 Huertas Vázquez 1989: 96.

7 Waeber 2005: 17-50.

8 Subirá 1949: 251-254.

9 Subirá dedicó amplias secciones de su libro a trazar la biografía de Iriarte (1949: 51-134) y a transcribir el texto íntegro (1950: 471-482) y el inicio de los diez números musicales de Guzmán el Bueno (1950: 491-502). La obra fue recuperada en concierto en mayo de 1996 por José Luis Pellicena y la Camerata del Prado bajo la dirección de Tomás Garrido en el Museo Municipal de Madrid. Más tarde, en septiembre de 2007, los mismos intérpretes la ejecutaron en el Aula Magna de la Universidad de Jaén.

10 Subirá 1950: [422]-[427].

11 Subirá 1950: 396.

12 Labrador López de Azcona 2008: 440. 
análisis de las tipologías de melólogo en Europa al comienzo de su monografía ${ }^{13}$, gracias a ello se impuso el término melólogo en la historiografía española. Ello a diferencia de lo ocurrido en la investigación musicológica internacional, que ha optado por el término melodrama $^{14}$, con excepción de la italiana ${ }^{15}$.

El melólogo podía ser para uno o varios personajes, y sus argumentos solían ser muy variados, con un marcado énfasis en los temas mitológicos e históricos (tanto nacionales como clásicos), una trama argumental simplificada con personajes estereotipados y un final dramático con la inevitable muerte o suicidio del protagonista. Junto con el trágicoheroico, hubo otros melólogos pertinentes a costumbres, religión, mitología y hasta burlescos ${ }^{16}$. Un subtipo escaso es el de ambientación americana, y ello a pesar del interés que los dramaturgos de la época tuvieron por temas indianos en clara continuación de la tradición originada en el teatro áureo del barroco ${ }^{17}$. El negro sensible del popular escritor Luciano Francisco Comella (1751-1812) es uno de ellos. Aunque este dramaturgo ya fue objeto de interés por parte de Subirá, ha sido María Angulo Egea quien ha documentado su carrera como autor de melólogos, analizando su papel en la modernización de las formas dramáticas tradicionales y estudiando la significación de la música en su ideario ${ }^{18}$. El más temprano de sus quince melólogos, Doña Inés de Castro (escrito en 1791, el mismo año del estreno del Guzmán de Iriarte en Madrid), es también uno de los que presenta una combinación más sofisticada de texto declamado, música orquestal, pantomima y estatuaria (con los figurantes permaneciendo inmóviles, a modo de tableau vivants o cuadro vivo) ${ }^{19}$. Sus melólogos son verdaderos productos multimedia con una concepción del hecho teatral como obra de arte total donde la música instrumental, desprovista de palabras, se convierte en el lenguaje primigenio de los sentimientos ${ }^{20}$. Ello hace del género melologal una de las primeras y más claras expresiones estéticas de la concepción romántica de la música en el área hispánica ${ }^{21}$. Por otro lado, y desde una perspectiva estrictamente musical, los melólogos sirven para ampliar nuestro conocimiento de la composición instrumental en el cambio de siglo, pues hasta ahora la investigación ha privilegiado el estudio de géneros canónicos como la sinfonía, la sonata y el concierto con el propósito de equiparar la práctica ibérica con la "gran" tradición austro-germánica, obviando fórmulas singulares de gran arraigo local como el melólogo²2.

13 Subirá 1949: 13-50.

14 Schwarz-Danuser 1996, y Branscombe 2001.

15 Scarton 1998.

16 Palacios Fernández 2008: 581-582.

17 Respecto de la representación del indiano en el teatro neoclásico, ver Rípodas Ardanaz 1986. Específicamente de las tonadillas de indianos y afroamericanos, ver Fernández-Cortés 2007b.

18 Subirá 1953; Angulo Egea 2006: 283-323.

19 Existe edición moderna (texto y música) a cargo de Angulo Egea, Labrador López de Azcona y García Martínez 2005. La pieza fue interpretada por la Camerata del Prado de Tomás Garrido en el Auditorio de Conde-Duque de Madrid en marzo de 2007 y grabada por Radio Clásica (Radio Nacional de España).

20 Labrador López de Azcona 2008: 441.

21 Relativo a la música instrumental y la concepción romántica de este arte, ver Fubini 1992: 253-296.

22 Marín y Bernadó 2014: 7-9. 
Reparto y sinopsis argumental

El negro sensible es un melólogo pluripersonal en un acto con un reparto de ocho personajes: el negro Catul, esclavo de Jacobo, un despiadado mercader; Doña Martina, una rica dama de ideas liberales que se acompaña de su hijo Juanito, su mayordomo Don Vicente y su criada Inés; completan el reparto un niño negro hijo de Catul, que no habla, y varios esclavos más. La escena se finge en un paraje idealizado de América, como señala la acotación de inicio que sirve de eficaz ambientación:

Sitio delicioso, poblado de árboles del país; casa con puerta practicable; un ingenio de azúcar corpóreo, que le deben andar tres negros; diferentes chozas repartidas por la escena, una cubierta de cañizos; un árbol capaz de ocultar una persona; banquillo de peñasco al pie; una fuente al foro [sic] rodeada de árboles. Al correrse el telón se ven varios negros durmiendo sobre una estera cada uno; en la choza primera estará Catul abrazado con un niño; va despertando poco a poco, corto piano, que imita el silencio de la noche y de las acciones de Catul. Teatro oscuro ${ }^{23}$.

El texto está compuesto por unos 400 versos endecasílabos, y todos los ejemplares consultados del libreto confirman una característica ya detectada por Catherine Raffi-Béroud: la ausencia de subdivisiones en escenas ${ }^{24}$. Su argumento toca un tema delicado en la época como el de la esclavitud, visto desde la nueva racionalidad ilustrada donde priman los ideales del "buen salvaje" y los valores de libertad e igualdad. La obra comienza con un largo parlamento del protagonista, el negro Catul, quien trabaja en un ingenio azucarero. El esclavo es sensible y sufre las consecuencias de su destino: su amo Jacobo lo ha separado de su esposa y solo le queda como consuelo su hijo, con quien se abraza tiernamente mientras amanece. El patrón despierta al resto de esclavos a golpe de látigo para iniciar una nueva jornada de trabajo y entabla un diálogo con Catul acerca de la falta de sensibilidad de los embrutecidos negros; tras lamentarse nuevamente por su desdicha, Catul besa los pies del amo y antes de marcharse da un último abrazo a su retoño. Poco después Jacobo sale a recibir a Doña Martina, una rica viuda española que llega a la hacienda acompañada de su hijo Juanito, su mayordomo Don Vicente y su criada Inés; tras alabar las bondades del paraje, Martina exhorta a Jacobo a que trate a los negros con piedad, a semejanza de los blancos, y lo convence para que los dispense de trabajar ese día. Los esclavos, agradecidos, se postran ante ella, mientras su hijo Juanito va a ver al negrito hijo de Catul, quien le regala frutas. Martina no puede ver miserias y manda preguntar a su mayordomo por el precio del negrito para comprarlo y darle mejor vida en España.

Catul aparece entonces en escena con un haz de cañas y busca sin éxito a su hijo, pero Jacobo le indica que el pequeño ya no es su esclavo, lo que provoca el desmayo del negro. Martina socorre a Catul, quien se sorprende por su trato humanitario y se lamenta una vez más de la injusticia que supone ser esclavo, privado ahora no solo de esposa sino también de hijo. Sabiendo por Jacobo que su hijo había partido con Martina pero desconociendo las verdaderas intenciones de la dama, Catul se enfurece. Entretanto, el negrito, que sigue en el ingenio, busca en vano a su padre mientras lo reconforta Martina, quien lee un libro

23 BHM, C-18860-5, p. 1. Los apuntes manuscritos presentan unas acotaciones ligeramente más desarrolladas. Para las fuentes, ver el siguiente epígrafe.

24 Raffi-Béroud 1998: 170, nota 116. 
de máximas en defensa de la libertad y la mujer. Oculto tras un árbol, un vengativo y enajenado Catul se acerca a la choza para apuñalar a Juanito, a quien cree hallar dormido junto a su madre. Antes del fatal desenlace, Martina levanta un pañuelo que oculta el rostro del niño y Catul descubre que se trata de su propio hijo. En ese momento, el esclavo se lamenta amargamente. Martina acaba perdonando al negro y decide liberarlo junto con su hijo para reunirlos con su esposa Bunga y llevarlos a España, donde trabajarán no como esclavos sino como criados a condición de que abandonen los cultos a sus dioses. Tras el gesto magnánimo de la rica viuda, Catul acepta convertirse al cristianismo y su aversión hacia los blancos y su religión se convierte ahora en alabanzas por su grandeza y generosidad. Como cualquier otra narrativa producida desde la cultura hegemónica, El negro sensible legitima la acción del hombre blanco como raza "superior"; el negro abandona su consideración de esclavo pero sigue estando sometido, ahora como criado. El argumento no hace sino afianzar las jerarquías existentes que sitúan en la cúspide los ideales civilizadores del hombre blanco, su despotismo y su religión ${ }^{25}$.

\section{Representaciones, fuentes y fortuna crítica}

La obra se estrenó en el Teatro del Príncipe de Madrid el 25 de agosto de 1798 en una solemne función de teatro comercial en la que participaron las dos compañías adscritas a los coliseos municipales del Príncipe y de la Cruz (ver Figura 1). Según informa el Diario de Madrid, la representación comenzó a las 5 de la tarde e incluyó, además de este melólogo, la comedia en dos actos Amor al dote con texto de Luciano Comella y música de Pablo del Moral. Con el reconocido actor Manuel García Parra en el papel de Catul, la función resultó todo un éxito y se dieron siete representaciones seguidas el 26, 27, 28 y 30 de agosto, y 1 y 2 de septiembre, con cuantiosos beneficios en taquilla. El mismo diario señala que el melólogo se repuso en la capital madrileña en 1801, 1802, 1809 y $1811^{26}$.

Asociadas al estreno se han conservado diversas fuentes documentales en la Biblioteca Histórica Municipal de Madrid. Un primer conjunto son los apuntes (o "apuntos" según denominación de época), manuscritos e impresos que contienen, además del texto dramático, el reparto del estreno y diversas indicaciones para su puesta en escena realizadas por el apuntador, el encargado de la escenografía o el propio autor. De El negro sensible existen varios apuntes manuscritos -algunos en doble copia-con numeración original en su portada (" 1 ", " $2^{\circ}$ " y " $3^{\circ}$ "), que se relacionan con las distintas funciones de cada fuente en el proceso de representación escénica: apuntar el texto a los actores, marcar su movimiento escénico y señalar al tramoyista los efectos de luz, sonido y cambio de decorados (ver Anexo 1) ${ }^{27}$.

25 González-Contreras 2016: 73.

26 Diario de Madrid, № 239 (27 de agosto, 1798), p. 962; No 240 (28 de agosto, 1798), p. 966; No 242 (30 de agosto, 1798), p. 976; $\mathrm{N}^{\circ} 244$ (1 de septiembre, 1798), p. 984; $\mathrm{N}^{\circ} 245$ (2 de septiembre, 1798), p. $988 ; \mathrm{N}^{\circ} 9$ (9 de enero, 1801), p. 36; $\mathrm{N}^{\circ} 132$ (12 de mayo, 1802), p. 529; $\mathrm{N}^{\circ} 133$ (13 de mayo, 1802), p. 534; $\mathrm{N}^{\mathrm{o}} 134$ (14 de mayo, 1802), p. 538; $\mathrm{N}^{\mathrm{o}} 135$ (15 de mayo, 1802), p. 542; $\mathrm{N}^{\mathrm{o}} 136$ (16 de mayo, 1802), p. 546; $\mathrm{N}^{\circ} 313$ (9 de noviembre, 1809), p. 524; y N 33 (2 de febrero, 1811), p. 135 (en esta última fuente se alude a El negro sensible como "gran comedia"). La prensa documenta la interpretación de la obra en Palma de Mallorca el 10 de abril de 1812 (Diario de Palma, No 101, p. 436) y el 17 de abril de 1817 (Diario Balear, No 278, p. 4).

27 Aguerri Martínez 2008: 484-487. 


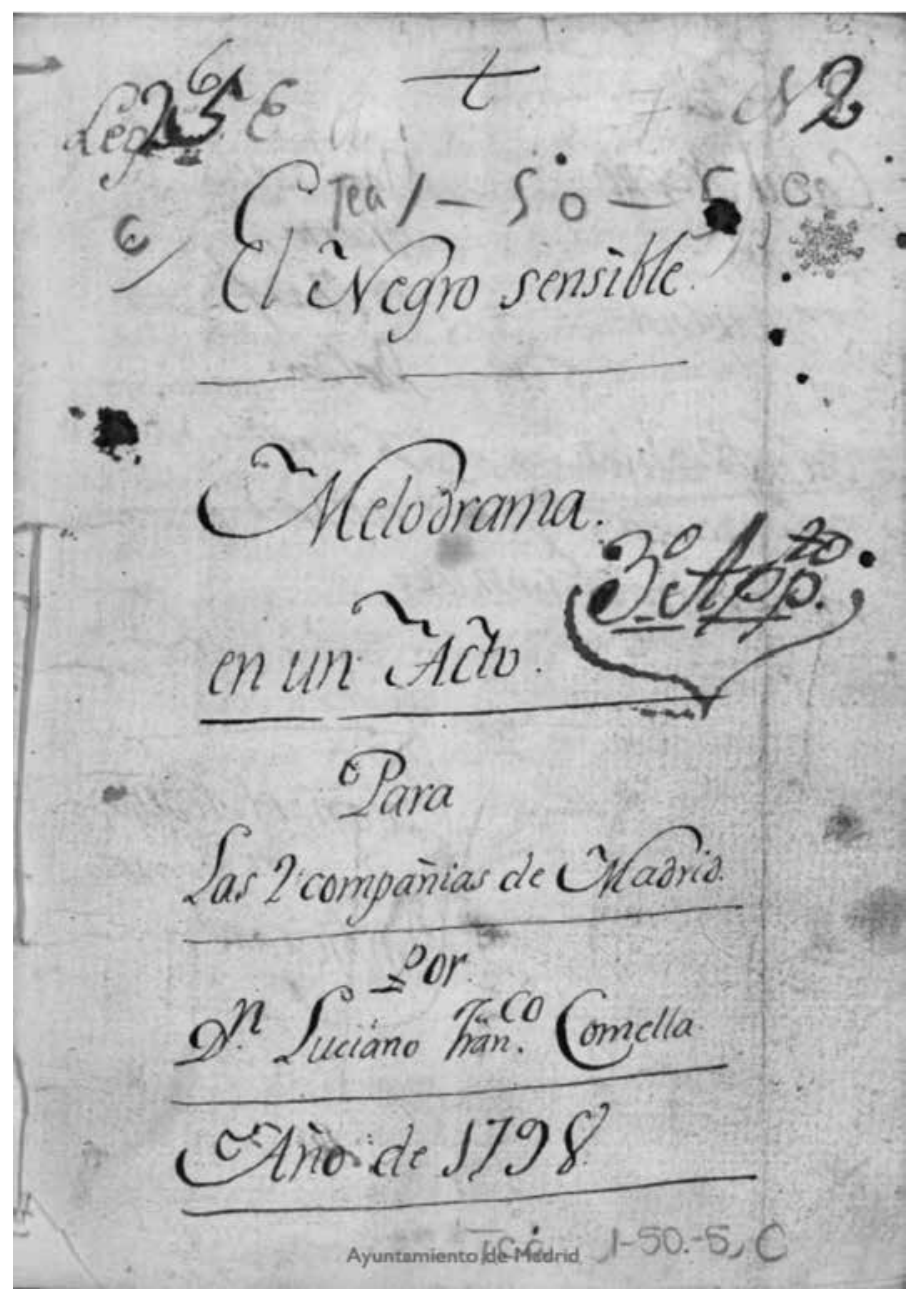

Figura 1. Portada del libreto manuscrito empleado en el estreno de El negro sensible en el Teatro del Príncipe de Madrid.

(Fuente: Madrid, BHM, Tea 1-50-5, C, fol. [1r]).

Respecto de la música, que Subirá dio por perdida ${ }^{28}$, se conserva en el mismo archivo un ejemplar de la partitura con doce números musicales, presumiblemente los que se interpretaron en el estreno de $1798^{29}$. La fuente no precisa el compositor, pero entre los posibles candidatos hay que mencionar a Pablo Esteve, Blas de Laserna, fecundo

28 Subirá 1950: 320.

29 AHMM, Mus. 22-20. Según la descripción del catálogo en línea, se conservan once partichelas para violín $1^{\circ}(2$ copias $)$, violín $2^{\circ}(2$ copias $)$, viola, flauta, oboe $1^{\circ}$, oboe $2^{\circ}$, trompa $1^{a}$, trompa $2^{\mathrm{a}}$ y bajo. 
colaborador de Comella ${ }^{30}$, y Pablo del Moral, quien era el principal compositor de las compañías teatrales madrileñas en la década de 1790 y el autor de la comedia estrenada en la misma función que El negro sensible. A ellos debe añadirse José Nonó, de quien en 1800 el Diario de Madrid ponía a la venta justamente "12 intermedios de música de la comedia intitulada el Negro sensible" 31 .

Como tantos otros melólogos de Comella, El negro sensible fue severamente censurado por los teóricos del teatro neoclásico. La crítica publicada en el Diario de Madrid el 14 de septiembre de 1798 y firmada por "Y. B." se dirigía a la cursilería del título, utilizado por los dramaturgos como reclamo publicitario ante el público; el crítico admitió que por ese motivo no quiso asistir a la función pese a su afición al teatro, y se quejaba de que el periódico le diese publicidad ${ }^{32}$. Casi cien años después de su estreno, Carlos Cambronero condenaba la obra sin paliativos: "el melodrama es realmente malo; pero no cabe duda de que el autor de El negro sensible sabía tocar la cuerda sensible del auditorio para quien escribía"33. Pese a ello, la obra gozó de popularidad en la península, pues además de las impresiones de Madrid y Salamanca se realizaron otras en Valencia (1801, 1814, 1817 y 1820), Sevilla (1816) y Barcelona (sin fecha), omitiendo siempre el nombre del compositor $^{34}$. Es probable que en estas representaciones el texto y también la música sufriesen reducciones, transformaciones y recomposiciones locales, prácticas frecuentes en las reposiciones del teatro breve ${ }^{35}$.

\section{El negro sensible en el Nuevo Mundo}

La fama de los melólogos, en particular los de Comella, no quedó circunscrita al ámbito peninsular sino que llegó a la otra orilla del Atlántico impulsada, por un lado, por la larga tradición de comedias y otros tipos teatrales con acompañamiento o inserción de música y, por otro, por el auge en la construcción de coliseos en las principales ciudades desde fines del siglo XVIII ${ }^{36}$. Todo ello supuso un estímulo para la creación de nuevos melólogos a cargo de dramaturgos y compositores criollos, un fenómeno que ha sido poco abordado por la musicología latinoamericana, la que ha concedido un tradicional protagonismo a la tonadilla sobre otros géneros breves ${ }^{37}$. En el caso de El negro sensible, las fuentes hemerográficas son de nuevo las que documentan el estreno de este melodrama -al parecer sin música ("De representado")- en el coliseo de la ciudad de México el 2 de diciembre de 1805, compartiendo cartelera con diversas tonadillas, un dúo de Manuel de Arenzana, maestro de capilla de la Catedral de Puebla, y varios bailes (ver Figura 2).

30 Labrador López de Azcona 2008: 439.

31 Diario de Madrid, № 237 (25 de agosto, 1800), p. 1000. Respecto de Nonó, ver Cuervo 2012.

32 "Tanta es la pedantería, tanta la afectación, tanto el aparato y ostentación vana con que nos presentan los autores sus obras, pretendiendo darnos altas ideas de ellas, llamar nuestra curiosidad con la novedad del título y en una palabra presentaros lo afiagaza [sic] para que caigamos en la red"; Diario de Madrid, No 257 (14 de septiembre, 1798), p. 1038.

33 Cambronero 1896: 482.

34 Referencias disponibles en www.worldcat.org. Subirá 1950: 322, informa de que El negro sensible se representó en Barcelona en tres ocasiones (11 de octubre, 1801; 11 de octubre, 1802; y 13 de septiembre, 1803).

35 Falk 2008: 361-364, ha estudiado algunos de estos cambios en los sainetes de Luis Moclín.

36 Claro Valdés 1981: 3-20.

37 Tello 2010: 46-53, y Eli 2010: 88-96. 
En uso del segundo beneficio qute por sut contrats debe idisfrutar el galán de música de este teatro VICTORIO ROCA'MORA," ha determinajo, execotarle hin' lunes it y' para com'placer a lós que tengan la bondad de concutrit 'as su aumento y lov - dithiento, ise exeeutarán las piezas sigaientes. De irepresentiado. 1. La maj majada. 2. Bl melodrama del Negro sensible. 3. El Soldado fanfarrot. De Cantado. El terceto del campanelo, por los Siês Maria Dolores Muoguia, Andrés del Castillo, y el interesado $L_{2}$ tonadilla á tres por los mir mos de la disputa de los amiges; y pot los dos ultimos un nuevo duo nombrado los dos ribales en amor, compuestó por el Muró. do - Capilla de la Sta. Iglesia Catedral de la Puebla de los Angeles D. Manuel Arenzana De Bavle. Unas boleras por los Srés. Guadalupe Gallardo y José Maria Morales, y for grande Siana y Siloio, del Mtrô. Sr. Juen Medina; sieado la entrada como dia de fiesta.

Figura 2. Programa con el estreno de El negro sensible en el coliseo de México.

(Fuente: Diario de México, № 63, 2 diciembre, 1805, p. 264).

Basándose en los libretos conservados en la Biblioteca Nacional de Argentina, Mariano Bosch y Vicente Gesualdo señalaron que El negro sensible se presentó en el coliseo de Buenos Aires a principios del siglo XIX ${ }^{38}$. Aún hoy se pueden consultar en ese recinto más de una decena de impresos de obras dramáticas de Comella representadas en las tablas porteñas. La mayoría no ofrecen fecha ni ciudad de edición, por lo que a priori podría pensarse que son impresiones locales ${ }^{39}$. Sin embargo, otros impresos llevan pie de imprenta en Valencia, Madrid o Barcelona, lo que apunta la hipótesis de que fueron los impresos peninsulares las principales fuentes utilizadas para la reposición americana de estas obras. De lo que no hay duda es de que el melólogo que nos ocupa fue conocido en Buenos Aires, quizá al mismo tiempo que en México.

La importancia del teatro como medio de control ideológico en toda la América hispánica se agudizó durante el inestable período insurgente, por lo que no es de extrañar que $E l$ negro sensible, ya perseguido por la Inquisición en España en 1806, también fuese prohibido en México en 1809 por promover "con capciosidad la insurrección de los esclavos contra sus legítimos dueños" 40 . Lejos de decrecer, su fama fue en aumento y el novelista criollo José Joaquín Fernández de Lizardi (1776-1827) escribió una segunda parte que publicó en 1825 , junto con la primera ${ }^{41}$. Esta versión se iba a representar en la capital mexicana el mismo año de su publicación, pero se canceló por oposición de los administradores del teatro. Finalmente, su estreno tuvo lugar el 11 de febrero de 1827, siendo la única obra teatral estrenada en vida del autor ${ }^{42}$.

38 BNRA, núm. 14.759, tomo 7; ver Bosch 1904: 159; Gesualdo 1961: 207.

39 Para los detalles, ver el catálogo en línea, http://catalogo.bn.gov.ar.

40 Gómez Álvarez y Tovar de Teresa 2009: 265.

41 Fernández de Lizardi 1825. Existe un ejemplar en impreso en la Yale University Library, Beinecke Rare Book and Manuscript Library, Mexico He93m 343. El mismo ejemplar está disponible en formato digitalizado en el sitio web de esta institución, mientras la segunda parte está disponible en Biblioteca Virtual Miguel de Cervantes (referencias en bibliografía).

42 Reyes Palacios 2004: 586 y 588. 
En esta secuela Fernández de Lizardi respetó el metro endecasílabo de Comella, pero amplió el número de versos, omitió figuras secundarias como Inés y añadió dos nuevos personajes: Enrique, otro esclavista español amigo de Jacobo, y Bunga, la esposa de Catul, mencionada fugazmente en la primera parte y ahora con un papel principal, pues todos los esfuerzos de la pudiente Doña Martina se dirigirán a liberarla del tirano Enrique ${ }^{43}$. Cada uno de los personajes mantiene su rol, aunque Fernández de Lizardi radicaliza sus sentimientos: Jacobo es aún más cruel e inhumano con los esclavos, Martina expone con más vehemencia sus ideales de justicia y humanidad, mientras que la irracionalidad y deseos de venganza de Catul son aún mayores. Tras varios episodios, Martina consigue comprar la libertad de Bunga y unir para siempre a la pareja de esclavos con su hijo, ya plenamente restituidos "al goce de los derechos que la naturaleza les concede" 44 . Aunque Fernández de Lizardi respeta la trama argumental propuesta por Comella, el contexto geográfico, político e ideológico en que escribe el criollo es radicalmente distinto al del dramaturgo español, lo que hace que esta secuela se vea resignificada. En 1825 México acababa de conseguir su independencia de España, de ahí que la libertad de Catul y su familia simbolice, en un plano más elevado, la autonomía y el civismo del nuevo Estado republicano y su oposición a las políticas totalitarias de la metrópoli y su entonces colonia cubana, donde la esclavitud aún no había sido abolida ${ }^{45}$.

Igual como ocurre con otros melólogos de su autoría como El Unipersonal de don Agustín de Iturbide, emperador que fue de México (1823), Fernández de Lizardi contempló la participación de la música. Una revisión del libreto muestra la existencia de seis acotaciones escénicas de carácter musical, todas excepto una requiriendo una "música triste". Esta adjetivación resulta ciertamente limitada considerando la variedad terminológica de los estados psicológicos que solían requerir los libretistas ${ }^{46}$, y es que para esa época el esplendor del melólogo ya había pasado. Se desconoce si la representación de 1827 incluyó participación instrumental. En todo caso, la presencia de números musicales en el teatro breve de Fernández de Lizardi merecería un estudio de conjunto que excede los límites de esta contribución y que permitiría arrojar luz sobre la recepción, consumo y creación de este singular género en la América hispana, dando así continuidad a los trabajos pioneros de Lauro Ayestarán en el Río de la Plata ${ }^{47}$.

\section{LA VERSIÓN DE RAMÓN GARAY PARA LOS MARQUESES DEL CERRO}

El hábitat natural de estos géneros teatrales breves eran los teatros públicos de Madrid y de otros núcleos urbanos de relevancia, tanto peninsulares como americanos. Sin embargo, consta que desde temprano estos mismos tipos dramáticos se cultivaron en el ámbito doméstico, tanto por la vía de la reducción y adaptación de textos y músicas a los medios locales disponibles como por la del encargo de nuevas composiciones respecto de los mismos libretos utilizados en los coliseos. Ya Subirá en su libro La música en la Casa de Alba documentó obras dramáticas de tonadilleros en el Palacio de Liria, y Juan Pablo

43 En esta sinopsis argumental sigo a Raffi-Béroud 1998: 152-163.

44 Fernández de Lizardi 1825: 63.

45 González-Contreras 2016: 74.

46 Subirá 1950: 405-406.

47 Ayestarán 1951: 3-10. 
Fernández-Cortés, en su estudio acerca de las casas de Osuna y Benavente, ha venido a confirmar la interpretación de tonadillas en las funciones privadas organizadas por María Faustina Téllez Girón en la década de $1780^{48}$. La existencia de una versión musical de El negro sensible compuesta por Ramón Garay para los marqueses del Cerro de la Cabeza indica que esta práctica -quizá más extensa y frecuente de lo que se imagina- también fue desarrollada en provincias por linajes periféricos como reflejo a pequeña escala de las fiestas patrocinadas por la alta nobleza en sus mansiones capitalinas.

\section{El compositor}

Bautizado en Santo Tomás de Sabugo, parroquia extramuros de la villa de Avilés (Asturias), Ramón Garay (1761-1823) probablemente inició su formación musical con su padre, organista de la real colegiata de Covadonga ${ }^{49}$. A los 18 años fue admitido como salmista y cantor en la Catedral de Oviedo, siendo discípulo del organista Juan Andrés de Lombida y del maestro de capilla Joaquín Lázaro. En 1785 se trasladó a Madrid, donde trabajó como maestro de música de los niños seminaristas del convento de los Jerónimos y completó su formación musical con José Lidón, prestigioso organista de la Real Capilla, maestro del colegio de niños cantorcicos y director de la orquesta de la condesa-duquesa de Benavente, que acababa de establecer un contrato con Joseph Haydn para el envío de nuevas composiciones. Su breve pero determinante paso por un centro de vanguardia como Madrid y su vinculación con una figura central como Lidón permitieron a Garay familiarizarse con las novedades musicales y teatrales de su tiempo, que incorporaría posteriormente a sus propias composiciones ${ }^{50}$. En septiembre de 1786 Garay escribió al cabildo eclesiástico de Jaén mostrando su interés por el magisterio de capilla entonces vacante (ver Figura 3). Después de unas multitudinarias y polémicas oposiciones, el maestro asturiano ganó la plaza y fue nombrado el 22 de mayo de 1787, permaneciendo en Jaén el resto de sus días. Pese a desarrollar su labor en una ciudad de provincias, Garay gozó de cierto reconocimiento en su época como así lo indican los anuncios de su música en la prensa madrileña ${ }^{51}$ y la invitación para dirigir la capilla real ante el rey Fernando VII en 1815, probablemente por mediación del citado Lidón, quien desde 1805 ejercía como maestro titular ${ }^{52}$.

48 Subirá 1927: 275-288; Fernández-Cortés 2007a: 340-353.

49 La biografía profesional más completa acerca de Garay es de Jiménez Cavallé 2011: 35-239. Capdepón Verdú (2011) realizó una síntesis basándose principalmente en fuentes secundarias.

50 Por su relación con el mundo teatral y su temática americana, es posible señalar que Lidón fue autor del drama lírico Glaura y Cariolano (estrenado en 1792), basado en el poema La Araucana de Alonso de Ercilla; ver García Fraile 1996.

51 En 1793 la librería de la calle Correa ponía a la venta una misa a dúo con órgano obligado "propia para los conventos y demás iglesias", obra que seguía anunciándose en 1797; Diario de Madrid, $\mathrm{N}^{\circ} 262$ (19 de septiembre, 1793), p. 1075, y Gazeta de Madrid, No 96 (1 de diciembre, 1797), p. 1060. Según el Legado Barbieri, sus obras se siguieron anunciando hasta el 8 de junio de 1802 (Casares 1984, vol. 1: 221).

52 Jiménez Cavallé 2011: 163-166. 


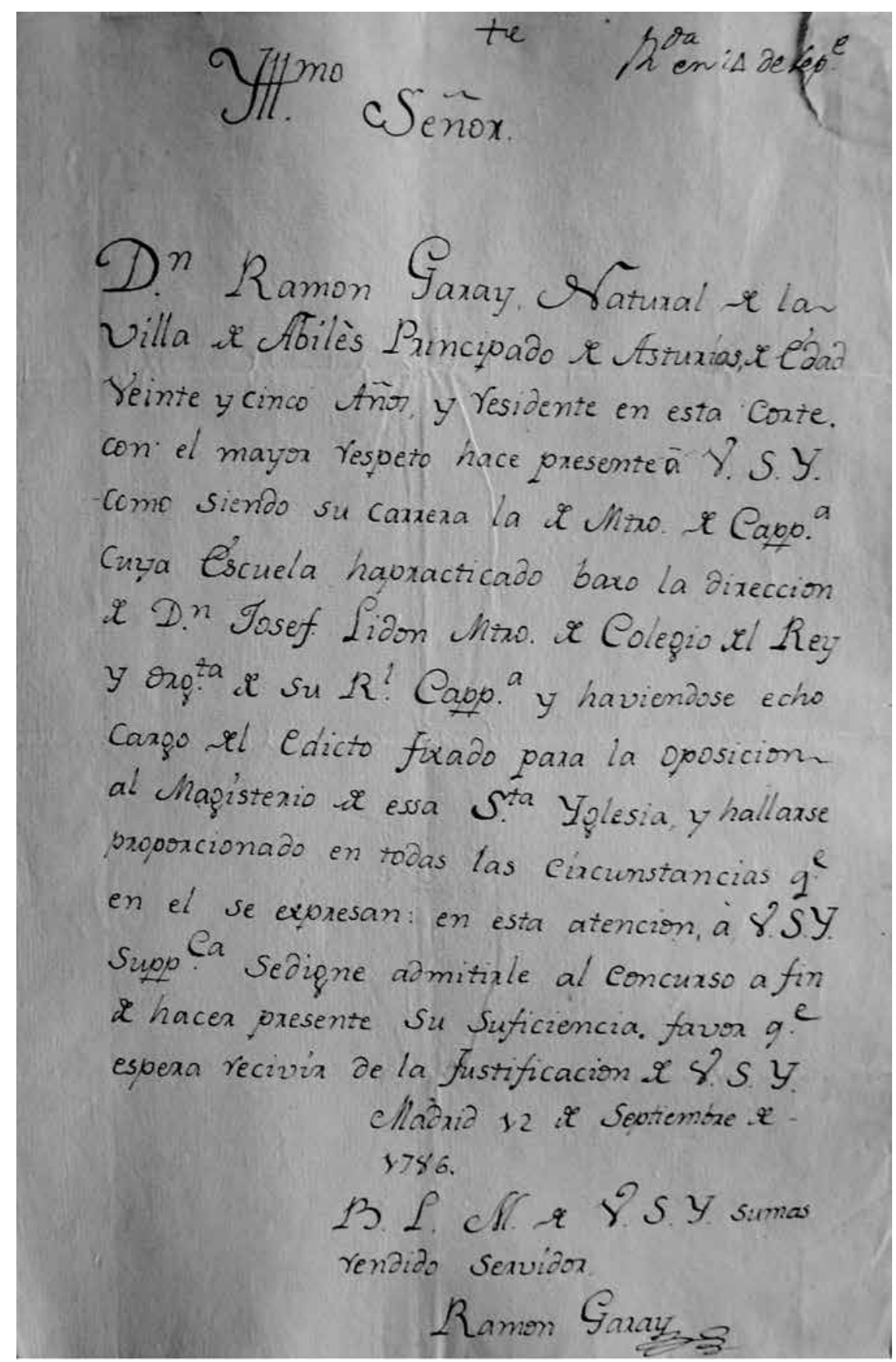

Figura 3. Carta de Ramón Garay al cabildo de la Catedral de Jaén.

(Fuente: Jaén, AHDJ, Archivo Capitular, Sección V, Carpeta de músicos, 12 de septiembre, 1786). 
Aunque Garay viene siendo objeto de atención musicológica desde los años 80, su labor como compositor religioso ha permanecido oculta hasta la reciente publicación de una extensa antología de obras ${ }^{53}$. Según el catálogo de Alfonso Medina se conservan en Jaén alrededor de 270 composiciones, lo que supone la práctica totalidad de su producción conocida (hay obras sueltas en archivos de El Escorial, Madrid, Oviedo, Orense, Zamora, Málaga, Granada y Antequera) ${ }^{54}$. Al igual que otros maestros de capilla, se trata en su mayor parte de piezas compuestas para el servicio litúrgico catedralicio, abarcando la mayoría de los géneros sacros, con un marcado énfasis en los responsorios y los villancicos, que suman unos dos tercios del total. Pero lo que singulariza el catálogo de Garay respecto de sus contemporáneos es la existencia de ciertas obras profanas y escénicas que han despertado la curiosidad de los especialistas en los últimos años: (1) el drama musical en dos actos Compendio sucinto de la Revolución Española (1815), una de las obras más ambiciosas de temática napoleónica ${ }^{55}$; (2) un Oratorio al Santísimo Sacramento dedicado -como el Compendio-al rey Fernando VII56; y (3) diez sinfonías (1790-1817), que conforman un corpus único y de gran relevancia en la historia de la música orquestal española por su temprana cronología y por la aparente escasez de obras de este género ${ }^{57}$. Este último dato es de especial interés si consideramos que El negro sensible está integrado por números puramente instrumentales que comparten algunas características con su producción sinfónica y que inciden en su rápida asimilación de las modernas tendencias imperantes en la capital madrileña.

\section{Contexto productivo y destinatarios}

Son escasos los detalles que conocemos del contexto productivo y la personalidad del mecenas destinatario de la obra que, según se anota en la parte superior de la primera página de la partitura, era el marqués del Cerro (ver Figura 4). La elección del argumento no parece casual: la sensible y refinada Doña Martina, defensora de los derechos de los esclavos, tenía título de marquesa. Por tanto, son la educación ilustrada, las virtudes morales y los medios económicos típicos de una aristócrata los que le permiten sacar a Catul y su familia del horror de la esclavitud. Con el encargo y representación de El negro sensible, el marqués del Cerro no solo proporcionaría a sus familiares e invitados un ameno pasatiempo, sino que además -por medio de una velada analogía- reforzaba su prestigio y su imagen como modelo de conducta a nivel local.

53 Capdepón Verdú (2016), incluye la edición de 60 piezas en castellano, en su mayoría villancicos.

54 Medina Crespo 2009: 120-192 (ítems 608-878); Jiménez Cavallé 2011: 259; Capdepón Verdú 2011: 25.

55 Pacheco Torres 2008 y 2010. La obra fue estrenada en diciembre de 2008 en Úbeda por La Grande Chapelle de Albert Recasens y grabada por Radio Clásica (RNE) en el marco de una coproducción entre la Sociedad Estatal de Conmemoraciones Culturales y el XII Festival de Música Antigua de Úbeda Baeza; ver Marín López y Sánchez López 2008: 67-86.

56 Su reposición moderna, acaecida en Madrid en febrero de 2011, corrió a cargo del citado Tomás Garrido y su Camerata del Prado; ver AA.VV. 2011: 15-21.

57 Todas las sinfonías (salvo la $\mathrm{N}^{\circ}$ 3) presentan una estructura en cuatro movimientos y una plena asimilación del estilo y la técnica del Clasicismo vienés, en particular de Haydn. Las sinfonías han sido analizadas en detalle por Jiménez Cavallé 2011: 260-517, publicadas por este mismo investigador (1996 y 2010) y grabadas por la Orquesta de Córdoba bajo la dirección de José Luis Temes (Ramón Garay. Las 10 sinfonias. 3 CDs. Madrid: Verso VRS2099, 2010). 


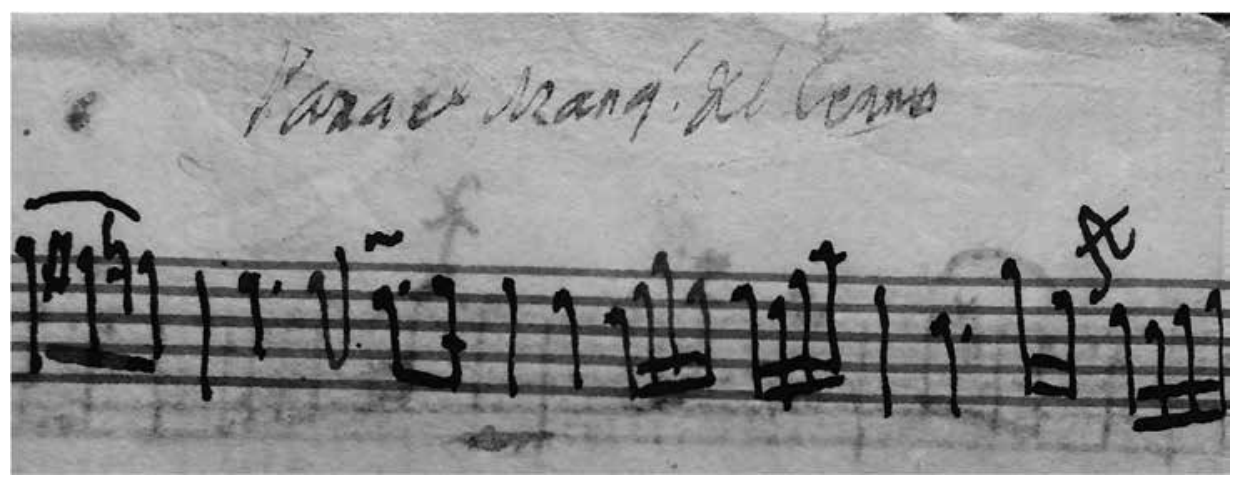

Figura 4. Dedicatoria de El negro sensible de Ramón Garay al marqués del Cerro.

(Fuente: Jaén, AHDJ, Archivo Musical, 40/2, fol. [1r]).

Debido a que hoy no existe un estudio de conjunto respecto del linaje de los marqueses del Cerro de la Cabeza, presento a continuación la información que he podido reunir de esta desconocida casa aristocrática. Su historia se inicia el 17 de enero de 1698, cuando Carlos II creó el título para su gentilhombre de cámara Alonso Diego de Tavira Osorio y Piédrola (1659-1723) en reconocimiento a sus méritos y servicios ${ }^{58}$. Parece que además de su fortuna personal fueron sus trabajos como servidor de la Casa del Rey los que se vieron recompensados con uno de los más excelsos honores que el monarca podría otorgar ${ }^{59}$. El título tomaba su nombre del Cerro de la Cabeza, paraje situado en plena Sierra Morena a 32 kilómetros de la ciudad de Andújar (provincia de Jaén) y que formaba parte de un mayorazgo fundado por Cristóbal de Piédrola en 1525, heredado en octava generación por Tavira Osorio y convertido en 1698 en marquesado ${ }^{60}$. La concesión de tal merced contó con la oposición del ayuntamiento de la ciudad, la cofradía de la Virgen de la Cabeza y el obispado de Jaén y originó un largo pleito no resuelto hasta 1945, pues el decreto real indicaba que eran propiedad del marqués ciertas dehesas que incluían el lugar donde, según la tradición, se produjo una aparición milagrosa de la Virgen en el siglo XIII. Para conmemorarla se construyó una ermita, luego transformada en santuario, que se convirtió en un importante centro de peregrinación ${ }^{61}$.

Fallecido el fundador, su nieto Félix Rafael de Tavira y Godoy (†1806) abonó la correspondiente media-annata para poder hacer uso del título, siendo confirmado como II marqués por Carlos III en $1781^{62}$. Su hijo y sucesor será José Francisco de Paula Tavira y Velluti (1777-1836), III marqués del Cerro y probable destinatario de El negro sensible. Tavira y Velluti dará un impulso al linaje por medio de su matrimonio con María Antonia de Montalvo y Dávila-Ponce de León (1784-1809). Con el nacimiento de su única hija en

58 AA.VV. 2001: 328.

59 Por la cercanía con los monarcas, el servicio como criado de palacio era una de las fórmulas predilectas para obtener un título nobiliario en la época, según Felices de la Fuente 2012: 232-240.

60 Torres Martínez 2010: 140.

61 Toral y Fernández de Peñaranda 1977: 11-13, 21-25.

62 AHNM, Consejos, 5240, exp. 6, 21 de junio, 1781. 
1809, María de la Cabeza de Tavira y Montalvo, Tavira y Velluti sumó a su fortuna la de los marquesados de Torreblanca y Falces y el condado de Santesteban de Lerín ${ }^{63}$. Fue un liberal de notorio compromiso político que llegó a ocupar diversos puestos de relevancia, entre ellos el de primer alcalde constitucional de Andújar entre octubre de 1812 y octubre de $1813^{64}$, diputado de la recién instituida Diputación Provincial ${ }^{65}$ y gobernador civil de la provincia entre junio de 1834 y agosto de $1835^{66}$, poco antes de su muerte, de la que se dio noticia en las Cortes ${ }^{67}$. Pese a moverse ya en los albores de las revoluciones burguesas, Tavira y Velluti siguió los patrones de conducta profesional del patriciado urbano tradicional y desempeñó funciones en cabildos municipales y otras instancias de gobierno como símbolo de prestigio y preeminencia.

Como oligarca dueño de extensas haciendas, no es de extrañar que Tavira y Velluti fuese caballero de la Real Maestranza ${ }^{68}$, ya que el arte ecuestre siempre fue una de las estrategias de distinción y señas de identidad de la clase aristocrática. De sus inclinaciones artísticas da cuenta su formación en la escuela de dibujo de Granada y la creación y mantenimiento en Andújar de una escuela gratuita de diseño, creada en 1804 con permiso del rey y de la Real Academia de Bellas Artes de San Fernando ${ }^{69}$. Aunque Tavira y Velluti mantenía vínculos con Granada, el centro de sus actividades y lugar de residencia era el antiguo castillo almohade de Andújar, derruido en 1932 y hoy solo conocido por fotografías (ver Figura 5). Sería en este palacio donde hipotéticamente tendría lugar la representación del melólogo en un momento que no ha podido precisarse. Tampoco hay indicios de quiénes pudieron ser los intérpretes. Es probable que, siguiendo una característica extendida de este tipo de tertulias domésticas, algunos miembros de la familia -en particular mujeres- participasen en la representación junto con músicos profesionales que podrían proceder de la propia ciudad de Andújar (donde había varias capillas de música) o de Jaén capital ${ }^{70}$.

63 AHNM, Consejos, 11988, exp. 28, 9 de octubre, 1809.

64 Torres Laguna 1981: 424 y 431. Por fuentes hemerográficas sabemos que Tavira también fue alcalde en la década de 1820; ver Mercurio de España, octubre, 1828, p. 264.

65 El Conciso, $\mathrm{N}^{\mathrm{o}} 30$ (30 de junio, 1813), p. 8. En 1820 figura en diversos medios como suplente de diputado a Cortes por la provincia de Jaén; ver El Universal observador español, $\mathrm{N}^{\circ} 19$ (30 de mayo, $1820)$, p. 69.

66 Diario Balear, $\mathrm{N}^{\circ} 87$ (26 de junio, 1834), [p. 1], y No 52 (21 de agosto, 1835), [p. 1 ].

67 El Español, $\mathrm{N}^{\mathrm{o}}$ 527, 12 de abril, 1837, p. 2. El testamento de Tavira y Velluti, fechado el 21 de noviembre de 1836, se conserva en Madrid, Archivo Histórico de Protocolos, protocolo 23926, fol. 577, según Matilla Tascón 1984: 28.

68 Fernández de Bethencourt 1908: 140-141. Junto con el título de maestrante se citan otros como el de alcaide perpetuo y regidor preeminente de Andújar, prócer del reino y gentilhombre de cámara con ejercicio del rey.

69 La escuela estuvo funcionando de manera provisional hasta 1805; ver Real Academia de Bellas Artes de San Fernando [1805]: 9-10.

70 En varias ocasiones la capilla de música de la Catedral de Jaén se trasladó con su maestro a Andújar, como ocurrió en 1816; ver Jiménez Cavallé 1998: 402 (Nº 5498). 


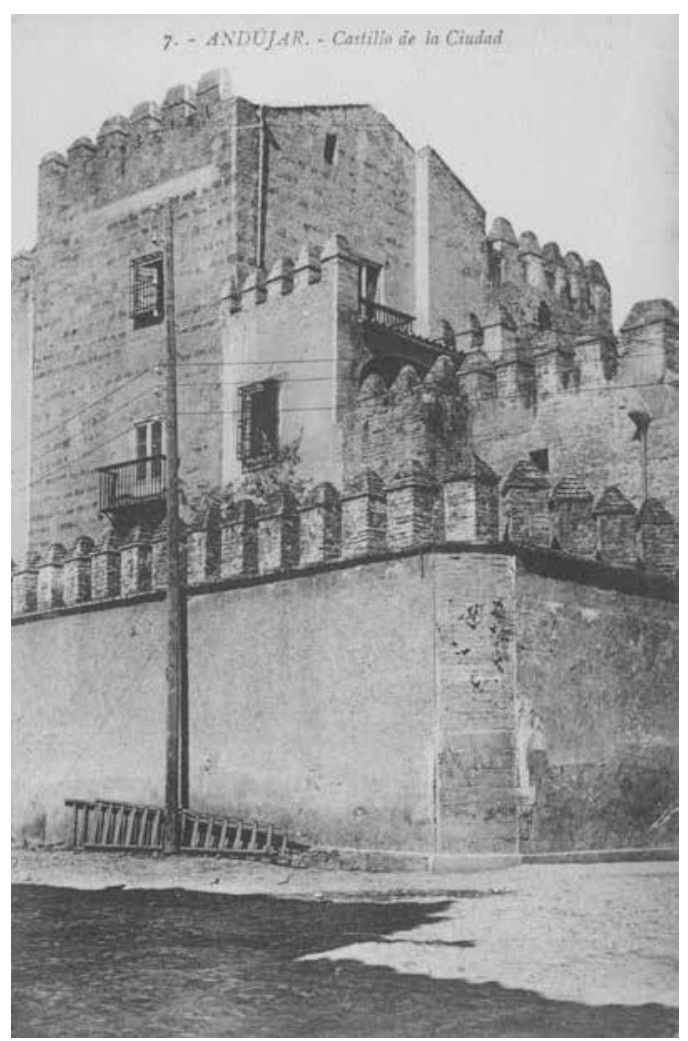

Figura 5. Palacio de los marqueses del Cerro de la Cabeza en Andújar.

(Fuente: Jaén, IEG, Fotografías en papel, A-284-7/1).

Se desconoce la fecha y las circunstancias en que Garay entró en contacto con los marqueses del Cerro y si (como parece lógico) ejerció de director o maestro de música de los mismos. En todo caso, las evidencias acerca del mecenazgo musical de este linaje no se restringen a El negro sensible. En la Catedral de Jaén se conserva otra pieza de Garay titulada Canten las ninfas todas, compuesta para festejar el matrimonio de Tavira y Velluti con su prometida María de Montalvo en $1806^{71}$. Es una composición celebrativa para dos voces (que representan a dos musas), dos violines, dos trompas y acompañamiento. Su estructura multiseccional alterna números a dúo con otros para solista (“canciones"), un recitado y un número coral de cierre muy efectista que actúa como fin de fiesta. En su conjunto, la obra se inscribe en una tradición encomiástica barroquizante en la que las musas ensalzan cantando las virtudes de los contrayentes y el triunfo de la unión y la fidelidad de los Tavira

71 AHDJ, Archivo Musical, 42/3. La portada presenta la siguiente inscripción: "Borrador / Letras en Celebridad del Casamiento del $S^{\text {or }}$. Marques del Cerro con la S $^{\text {ra }}$. Marq ${ }^{\text {sa }}$ de Torreblanca / Puesta en Musica / Por d $\mathrm{d}^{\mathrm{n}}$. Ramon Garay Prebendado y / Mtro de Capilla de la / Sta. Ygla . De Jaen / Año de 1806". 
y los Montalvo. Consta asimismo que Garay compuso música de cámara, en concreto varios tríos, probablemente destinados al ámbito doméstico ${ }^{72}$.

Procesos de adaptación musical y dramatúrgica

La versión musical de Garay de El negro sensible se conserva en la Catedral de Jaén en una única copia, en formato partitura, formando un cuadernillo autógrafo de seis folios apaisados $\sin$ portada ${ }^{73}$. Es altamente probable que Garay se basara en alguno de los ejemplares impresos del texto de Comella que circulaban en España, posiblemente el de Madrid, a tenor de las coincidencias casi literales con las acotaciones manuscritas de la partitura (ver Anexo 2). El cotejo de la versión musical de Garay con las fuentes literarias conservadas en la Biblioteca Histórica Municipal de Madrid y el estudio de las acotaciones incorporadas por el propio compositor en la partitura indican que realizó una adaptación dramatúrgica que afectó no solo al total de intervenciones musicales y a la plantilla instrumental utilizada, sino también a la compleja articulación de texto, música y dramatización. La transcripción moderna de esta partitura se ofrece como anexo electrónico a este trabajo ${ }^{74}$.

Del total de once números musicales deducibles del libreto impreso ${ }^{75}$, el maestro asturiano compuso ocho (ver Tabla 1), prescindiendo de musicalizar la escena en que Jacobo despierta a los negros a latigazos ( $\left.\mathrm{N}^{\circ} \mathrm{II}\right)$, el momento en que Catul se dispone a dar muerte a Juanito $\left(\mathrm{N}^{\circ} \mathrm{X}\right)$ y la escena final en la que el esclavo se reencuentra con su hijo $\left(\mathrm{N}^{\circ} \mathrm{XI}\right)^{76}$. Por otro lado, la plantilla requerida por Garay es más reducida, limitándose a dos violines, dos flautas y acompañamiento (prescinde de la viola, las parejas de oboes y las trompas presentes en la versión teatral madrileña, que tendría más volumen sonoro), si bien añade un clave obligado en todos los números excepto en los dos primeros. La irrupción del clave en el $\mathrm{N}^{\circ}$ III, justo cuando Doña Martina entra en escena, y su despliegue de medios con pasajes a solo en momentos escénicos protagonizados por ella en ese y otros números (por ejemplo $\mathrm{N}^{\circ}$ IV, cc. 40-48 y cc. 57-77; $\mathrm{N}^{\circ}$ VIII, cc. 11-17 o cc. 25-29), permite establecer una correspondencia entre la dama y el instrumento concertante, que siguiendo una costumbre arraigada entre la aristocracia pudo ser tocado por el maestro Garay -hábil organista- o, especulando un poco más, por la misma María de Montalvo ${ }^{77}$.

72 La referencia a los tríos de Garay se encuentra en Sustaeta Llombart 1993: 246, citado por Bertran 2014: 413.

73 Hasta ahora la obra no había sido identificada como melólogo, de ahí que tanto Medina Crespo 2009: 185 (quien cita una signatura distinta a la actual: “39/8”), como Jiménez Cavallé 2011: 252, la titulen a partir de la primera acotación escénica, Catul se abraza con el niño.

74 Ver edición electrónica del presente número en https://revistamusicalchilena.uchile.cl.

75 La partitura anónima conservada en Madrid incluye doce números musicales quizá debido a que, como señala Labrador López de Azcona 2008: 442, los melólogos solían finalizar con un postludio instrumental que no se referencia en los apuntes manuscritos ni en las ediciones impresas.

76 Existe la posibilidad, musical y dramatúrgicamente verosímil, de que para esta escena se utilizase la primera parte del $\mathrm{N}^{\circ}$ I o el No II. En todo caso, el número de fragmentos musicales se sitúa por debajo del promedio de melólogos en un acto, según la "Tabla sinóptica" ofrecida por Subirá 1950: [422]-[427].

77 Sánchez López 2014: 490-511. A favor de esta hipótesis está el hecho de que en pasajes donde la presencia de Martina es de menor importancia dramatúrgica, el clave dobla a violines o flautas. 
TABLA 1. SECCIONES MUSICALES DE EL NEGRO SENSIBLE DE RAMÓN GARAY

\begin{tabular}{|c|c|c|c|c|}
\hline Sección & Plantilla & Compás/Tempo & Tonalidad & Extensión \\
\hline I & $2 \mathrm{vln}+2 \mathrm{fl}+\mathrm{ac}$ & $\begin{array}{c}3 / 4 \\
\text { Despacio Amoroso }\end{array}$ & do mayor & $\begin{array}{c}27 \mathrm{cc} . \\
(8+19)\end{array}$ \\
\hline II & $2 \mathrm{vln}+\mathrm{ac}$ & $\begin{array}{c}3 / 4 \\
\text { Despacio }\end{array}$ & la menor-do mayor & $22 \mathrm{cc}$. \\
\hline III & $2 \mathrm{vln}+2 \mathrm{fl}+$ clave obl. $+\mathrm{ac}$ & $\begin{array}{c}2 / 4 \\
\text { Andante }\end{array}$ & do mayor & $39 \mathrm{cc}$. \\
\hline IV & $2 \mathrm{vln}+2 \mathrm{fl}+$ clave obl. $+\mathrm{ac}$ & $\begin{array}{c}3 / 4 \mathrm{y} 6 / 8 \\
\text { Andante } \\
\text { Moderato } / \text { Allegro }\end{array}$ & la menor-do mayor & $\begin{array}{c}94 \mathrm{cc} . \\
(14+80)\end{array}$ \\
\hline V & $2 \mathrm{vln}+2 \mathrm{fl}+$ clave obl. $+\mathrm{ac}$ & $\begin{array}{c}\mathrm{C} \\
\text { Despacio }\end{array}$ & $\begin{array}{c}\text { do menor-mi bemol } \\
\text { mayor-do menor }\end{array}$ & $25 \mathrm{cc}$. \\
\hline VI & $2 \mathrm{vln}+2 \mathrm{fl}+$ clave obl. $+\mathrm{ac}$ & $\begin{array}{c}\mathrm{C} \\
\text { Allegro }\end{array}$ & mi bemol mayor & $34 \mathrm{cc}$. \\
\hline VII & $2 \mathrm{vln}+$ clave obl. $+\mathrm{ac}$ & $\begin{array}{c}6 / 8 \\
\text { Largo siempre piano }\end{array}$ & mi bemol mayor & $11 \mathrm{cc}$. \\
\hline VIII & $2 \mathrm{vln}+2 \mathrm{fl}+$ clave obl. $+\mathrm{ac}$ & $\begin{array}{c}2 / 4 \\
\text { Andante }\end{array}$ & si bemol mayor & $44 \mathrm{cc.}$ \\
\hline & & $296 \mathrm{cc}$. \\
\hline
\end{tabular}

Elaboración propia.

Con todo, el cambio de mayor alcance consiste en la nueva relación que Garay establece entre la declamación, la música instrumental y la representación escénica. Si en el modelo francés de melólogo seguido en el área hispánica la música se alterna con el texto, glosando o intensificando la acción dramática que acontece en escena, en la versión jiennense encontramos un uso más diversificado que trasciende su función primigenia. Por un lado, y en la línea de la variante alemana de melólogo, hay fragmentos que se recitan coordinadamente mientras suena la música de fondo, como ocurre con la respuesta del $\mathrm{N}^{\circ}$ I (cc. 9-27), que se interpreta como acompañamiento de la segunda declamación de Catul ("Ya parece que en brazos"), a excepción de los tres últimos versos y medio, que se declaman sin música (la partitura señala "y sigue solo" a partir de las palabras "ya debo abandonarte"). Por otro, y como claramente señala la acotación "sin que haya representación en nada de ella" que acompaña al $\mathrm{N}^{\circ}$ III, hay fragmentos que se interpretan como música instrumental pura, sin declamación ni representación, asumiendo un rol dramatúrgico análogo en importancia al del texto o al de la propia dramatización ${ }^{78}$. La música no solo glosa o completa el

78 Esta idea parece que formaba parte de las intenciones originales de Comella, pues en la acotación del libreto impreso figura la frase "toda esta escena la expresará la música"; BHM, C-18860-5, p. 3. 
sentido del texto declamado y la acción dramática, sino que los sustituye. En este caso, la música actúa, además, con un sentido de anticipación y expresa la alegría que supone la llegada al ingenio de Martina, a la postre futura libertadora del esclavo y su familia. Para expresar musicalmente la acción, Garay recurre a un brillante do mayor (venimos de un movimiento lento y melancólico en la menor), acelera el tempo e intensifica el movimiento rítmico por medio de valores más breves y pasajes de cierto virtuosismo encomendados al clave (cc. 10-11, 27-29). En otros casos, como el $\mathrm{N}^{\circ} \mathrm{IV}$, el maestro asturiano se apega a la convención melologuista y concibe un amplio movimiento instrumental como acompañamiento de la representación escénica que ayuda al avance de la trama: los negros se postran ante Doña Martina, agradecidos por haber persuadido a Jacobo para que no les haga trabajar ese día, mientras que la distracción de las criadas propicia el encuentro de Juanito con el negrito, que le obsequia con frutas del país. Se trata de un momento de especial intensidad emocional, tal y como se hizo notar Garay en la propia partitura: "Esta es una de las escenas más interesantes".

Por tanto, la música en El negro sensible no es un mero acompañamiento incidental de la acción sino que asume una amplia variedad de funciones expresivas y dramatúrgicas: guía la acción teatral expresada en el libreto, sustituye al texto y a la representación escénica, expresa con sus propios medios el drama interno del protagonista y desarrolla una función articuladora de la trama por medio de ocho números contrastantes en extensión, ritmo y carácter que llenan casi 300 compases de música con una duración aproximada de doce minutos, acercándose en extensión a la sinfonía más breve del autor, la $\mathrm{N}^{\circ} 8^{79}$. Estilísticamente, presenta las características propias de la música galante de salón: repertorio de naturaleza simple y relativamente fácil de ejecutar, con ocasionales secuencias y notas pedales, formas claras y esquemas armónicos lógicos (con preferencia por tonalidades mayores, modulaciones al relativo o al homónimo menor en movimientos lentos), ritmos pegadizos y simétricos, melodías cuadradas, arpegiadas y cantábiles en un estilo netamente europeo que por momentos recuerda al divertimento ( $\mathrm{N}^{\circ}$ III) o a la pastorela ( $\mathrm{N}^{\circ}$ VIII, cc. 18-24). En el contexto de un género afectuoso como el melólogo reviste particular importancia la combinación de indicaciones dinámicas contrastantes con tendencia a la gama media-baja ( $p p, p, m p, f p, s f z, p o c o f, f)$ y la presencia constante de retardos, pasajes cromáticos y apoyaturas que generan un efecto expresivo y disonante muy apropiado para insinuar un ambiente de tensión anímica. Quizás la característica más sobresaliente de la música de Garay sea su absoluta independencia respecto de la temática y al lugar donde transcurre la acción: no hay vestigio ni referencia alguna a la música, los bailes o los instrumentos de los negros u otras clases populares, aspecto que resulta definitorio de géneros breves como la tonadilla, el sainete o el entremés, sean de temática americana o no ${ }^{80}$. Garay y su música se alinean aquí con el tono grave del argumento de Comella, cuyo texto dramático tampoco hace uso de las ricas posibilidades lingüísticas de la figura del negro.

$79 \mathrm{Su}$ extensión ronda los 400 compases y su duración 14 minutos y medio, según la grabación de la Orquesta de Córdoba.

80 Labrador López de Azcona 2006; Fernández-Cortés 2007b. Con la inclusión de elementos locales se pretendía dotar de mayor realismo a la acción por medio de una ambientación sonora afín a los personajes. En sus sinfonías Garay sí incorpora elementos populares de claro sabor asturiano, según Jiménez Cavallé 2011: 432-440. 


\section{REFLEXIONES FINALES}

Hay razones para pensar que El negro sensible es una obra de importancia histórica y actual por cuanto ilustra procesos y fenómenos de amplio alcance en ambas orillas que al ser desconocidos no han sido lo suficientemente estudiados.

En primer lugar, invita a revisitar las funciones de la música en los melólogos y a recuperar para la historia de la música instrumental hispánica los números musicales insertos en esta curiosa tipología dramática.

En segundo lugar, documenta la continuidad de su cultivo en algunos de los principales coliseos hispanoamericanos, así como su diversificación en manos de creadores y compañías teatrales locales.

En tercer lugar, saca a la luz una faceta hasta ahora desconocida de Ramón Garay, compositor versátil que supo desenvolverse no solo en el ámbito de la música vocal sacra y profana y los géneros instrumentales puros, sino también en el teatro breve declamado con participación musical, que gozaba de gran aceptación desde el siglo XVI.

En cuarto lugar, se convierte en un testimonio que ejemplifica la labor de mecenazgo musical desarrollada en provincias por linajes periféricos. En el caso de los marqueses del Cerro de la Cabeza, dicha labor no solo pudo implicar la adaptación de obras teatrales a un contexto dramatúrgico distinto, sino también la composición de nuevas piezas en géneros innovadores de corte clasicista como el melólogo. Ello permite insertar las pequeñas casas de la nobleza hispánica dentro del circuito de difusión de los repertorios creados para los teatros públicos, aspecto del que convendrá seguir investigando en el futuro.

Más allá de lo anterior, y parafraseando a John Shepherd, El negro sensible constituye un interesante caso de estudio desde el paradigma de la historia cultural de la música, por cuanto refleja, modela y proyecta identidades, prácticas y experiencias de las clases socia${ }_{\text {les }}{ }^{81}$. Las razones de su calurosa acogida y su vigencia durante tres décadas en distintos ámbitos geográficos, marcos productivos y realidades sociales radican en su capacidad de adaptación y resignificación ideológica, llegando a adquirir valores contrapuestos: si en el coliseo público de México -y quizá también en el de Buenos Aires- era visto como arma propagandística al servicio de la nueva república independiente, en el entorno doméstico de los marqueses del Cerro legitima el prestigio y el poder de una élite aristocrática local en la antesala de las rupturas sociales del Liberalismo. En ambos casos, sin embargo, la estrategia de seducción era común y estaba socialmente construida: la expresión verosímil de sentimientos íntimos en público, apelando de manera franca a la emotividad del espectador por medio de un texto, una dramatización y una música que apelaban a diferentes estados psicológicos. Ello hizo que el melólogo, en ambas orillas y en sus diferentes contextos, se convirtiese en emblema de la nueva sentimentalidad y en el ideal expresivo, estético y simbólico de una época no exenta de contradicciones.

\section{BIBLIOGRAFÍA}

Artículos y libros

AA.VV.

2001 Elenco de grandezas y títulos nobiliarios españoles. Madrid, Ediciones de la Revista Hidalguía.

2011 XXI Festival de Arte Sacro de la Comunidad de Madrid, del 28 de febrero al 11 de abril de 2011 (libro-programa del festival). Disponible en www.madrid.org/artesacro/2011/prensa/pdf/ programa_general.pdf [último acceso: 3 de junio de 2019].

${ }^{81}$ Shepherd 2003: 69. 
Aguerri Martínez, Ascensión

2008 "Catalogación de los apuntes de teatro en la Biblioteca Histórica Municipal". Teatro y música en España: los géneros breves en la segunda mitad del siglo XVIII. Joaquín Álvarez Barrientos y Begoña Lolo, editores. Madrid: Universidad Autónoma de Madrid, pp. 481-490.

Álvarez BARrientos, JoAQuín

2005 "Pantomima, estatuaria, escena muda y parodia en los melólogos (a propósito de González del Castillo)". Juan Ignacio González del Castillo y el teatro de su tiempo. Alberto Romero Ferrer, editor. Cádiz: Ayuntamiento de Cádiz, Universidad de Cádiz y Grupo de Estudios del Siglo XVIII, pp. 259-293.

Angulo Egea, María

2006 Luciano Francisco Comella (1751-1812). Otra cara del teatro de la Ilustración. Alicante: Publicaciones de la Universidad de Alicante.

Angulo Egea, María, Germán labrador López de Azcona y J. Daniel García Martínez

2005 Luis Francisco Comella y Blas de Laserna: Doña Inés de Castro, escena trágico-lírica. Salamanca: Grupo de Estudios del Siglo XVIII y Ediciones Amnesia.

Ayestarán, Lauro

1951 "El melólogo. A propósito de los unipersonales de Bartolomé Hidalgo". Número, III/12, pp. 3-10.

BERTRAN, LLuís

2014 "Eligiendo las piezas: los tríos de Gaetano Brunetti y la recepción de la música instrumental europea”. Instrumental music in late eighteenth-century Spain. Miguel Ángel Marín y Màrius Bernadó, editores. Kassel: Edition Reichenberger, pp. 383-424.

Bosch, Mariano G.

1904 Teatro antiguo de Buenos Aires. Piezas del siglo XVIII, su influencia en la educación popular. Buenos Aires: Imprenta El Comercio.

Branscombe, Peter

2001 "Melodrama", Grove Music Online. Oxford Music Online. Stanley Sadie y John Tyrrell, editores. Oxford: Oxford University Press. Disponible en www.oxfordmusiconline.com.

Cambronero, Carlos

1896 "Comella", Revista Contemporánea, 103, pp. 479-491.

Capdepón Verdú, Paulino

2011 "Ramón Garay (1761-1823), maestro de capilla de la Catedral de Jaén", Cuadernos de Ilustración y Romanticismo, XV/17, pp. 1-27.

2016 El compositor asturiano Ramón Garay (1761-1823). 2 vols. Madrid: Fundación María Cristina Masaveu Peterson.

CASAREs, Emilio (eDitor)

1984 Francisco Asenjo Barbieri. Biografías y documentos sobre música y músicos españoles (Legado Barbieri). 2 vols. Madrid: Fundación Banco Exterior.

Claro-Valdés, Samuel

1981 "Música teatral en América", Revista Musical Chilena, XXXV/156, pp. 3-20.

Cuervo, Laura

2012 "José Nonó (1776-1845), compositor que fundó el primer Conservatorio de Música privado en Madrid", Anuario musical, 67, pp. 133-152.

ELI, Victoria

2010 "Nación e identidad en las canciones y bailes criollos". Historia de la música en España e Hispanoamérica. Vol. 6: La música en Hispanoamérica en el siglo XIX. Consuelo Carredano y Victoria Eli, editoras (Juan Ángel Vela del Campo, director y coordinador editorial). Madrid: Fondo de Cultura Económica de España, pp. 71-124. 
FALK, Heinrich R.

2008 "La participación musical en los sainetes de Luis Moclín”. Teatro y música en España: los géneros breves en la segunda mitad del siglo XVIII. Joaquín Álvarez Barrientos y Begoña Lolo, editores. Madrid: Universidad Autónoma de Madrid, pp. 351-375.

Felices de la Fuente, María del Mar

2012 La nueva nobleza titulada de España y América en el siglo XVII (1701-1746). Entre el mérito y la venalidad. Almería: Editorial Universidad de Almería.

Fernández-Cortés, Juan Pablo

2007a La música en las casas de Osuna y Benavente (1733-1882). Un estudio sobre el mecenazgo musical de la alta nobleza española. Madrid: Sociedad Española de Musicología.

2007b "Sonsonetes y cumbés: aproximación a las relaciones de la tonadilla escénica con el Nuevo Mundo a partir de algunas obras musicales de Luis Misón ( ca. 1720-1766) y Blas de Laserna (1751-1816)". La música y el Atlántico. Relaciones musicales entre España y Latinoamérica. María Gembero Ustárroz y Emilio Ros-Fábregas, editores. Granada: Universidad de Granada, pp. $437-453$.

Fernández de Bethencourt, Francisco

1908 Anuario de la nobleza de España. Tomo I. Anuario de la nobleza de España. Tomo I. Madrid: Establecimiento Tipográfico de Fortanet.

[FERnÁNDEZ de LizARdi, José JoAQuín]

1825 El negro sensible. Primera y segunda parte. Hecha la última por el Pensador Mexicano. México, Oficina del finado Ontiveros. Ejemplar digitalizado. Disponible en http://brbl-dl.library.yale.edu/ vufind/Record/3445483 [último acceso: 3 de junio de 2019]. Segunda parte disponible en Biblioteca Virtual Miguel de Cervantes, www.cervantesvirtual.com/obra/el-negro-sensiblesegunda-parte/ [último acceso: 3 de junio de 2019].

Fubini, EnRICo

1992 La estética musical desde la Antigüedad hasta el siglo XX. Madrid: Alianza Editorial.

García Fraile, Dámaso

1996 "Un drama heroico en verso castellano: «Glaura y Cariolano» de Joseph Lidón, representado en Madrid, en el tercer centenario del descubrimiento de América”. Teatro y música en España (siglo XVIII). Rainer Kleinertz, editor. Kassel: Edition Reichenberger, pp. 145-176.

Gesualdo, Vicente

1961 Historia de la música en la Argentina, 1536-1851. Tomo I. Buenos Aires: Editorial Beta.

Gómez Álvarez, Cristina y Guillermo Tovar de Teresa

2009 Censura y revolución. Libros prohibidos por la Inquisición de México (1790-1819). Madrid: Trama Editorial y Consejo de la Crónica de la Ciudad de México.

González-Contreras, Melissa

2016 "José Joaquín Fernández de Lizardi ante la libertad en El negro sensible y La tragedia del padre Arenas", Revista de producción cultural hispánica decimonónica, XIII/2, pp. 67-81.

Gujjarro Ceballos, Javier

2011 "El 'melólogo', el nombre de un género sin nombre", Anuario de estudios filológicos, 34, pp. 39-52.

Huertas Vázquez, Eduardo

1989 Teatro musical español en el Madrid ilustrado. Madrid: Ediciones La Librería.

Jiménez Cavallé, Pedro

1996 Ramón Garay. Sinfonías Nos. 5, 8, 9 y 10. Madrid: Instituto Complutense de Ciencias Musicales, Serie B, Música Instrumental, 9.

1998 Documentario Musical de la Catedral de Jaén. I. Actas Capitulares. Granada: Centro de Documentación Musical de Andalucía. 
2010 Ramón Garay. Sinfonías Nos. 1, 2, 3, 4, 6 y 7. Madrid: Instituto Complutense de Ciencias Musicales, Serie B, Música Instrumental, 38.

2011 Ramón Garay (1761-1823), un clásico, autor de 10 sinfonías. Jaén: Servicio de Publicaciones e Intercambio Científico de la Universidad de Jaén.

JONES, JOSEPH R.

2012 "María Rosa de Gálvez, Rousseau, Iriarte y el melólogo en la España del siglo XVIII". Alicante: Biblioteca Virtual Miguel de Cervantes. Disponible en www.cervantesvirtual.com/obra-visordin/maria-rosa-de-galvez-rousseau-iriarte-y-el-melologo-en-la-espana-del-siglo-xviii/html/ [último acceso: 3 de junio de 2019]

Labrador López de Azcona, Germán

2006 "Rasgos culturales de trascendencia sonora en la tonadilla escénica. A la búsqueda de un registro musicado del Madrid de finales del s. XVIII". III Jornadas Nacionales de Folclore y Sociedad. Ciudad Real: CIOFF España, pp. 151-172.

2008 "Momentos musicales en los melólogos de Laserna-Comella. Música, texto y pantomima en la escena madrileña de finales del siglo XVIII". Teatro y música en España: los géneros breves en la segunda mitad del siglo XVIII. Joaquín Álvarez Barrientos y Begoña Lolo, editores. Madrid: Universidad Autónoma de Madrid, pp. 439-458.

Marín, Miguel Ángel y Màrius Bernadó

2014 "Instrumental music in late eighteenth-century Spain: issues and challenges". Instrumental music in late eighteenth-century Spain. Miguel Ángel Marín y Màrius Bernadó, editores. Kassel: Edition Reichenberger, pp. 1-19.

MARín López, JaVier y Virginia SÁNChez López (EDitores)

2008 Sones de batalla: música y guerra en el mundo hispano (ss. XVI-XIX). XII Festival de Música Antigua de Úbeda y Baeza. Baeza: Festival de Música Antigua de Úbeda y Baeza.

Matilla Tascón, Antonio

1984 Índice de testamentos y documentos afines de nobles. Madrid: Ediciones Hidalguía.

Medina Crespo, Alfonso

2009 Catálogo del Archivo de Música de la Santa Iglesia Catedral de Jaén Granada: Centro de Documentación Musical de Andalucía.

Pacheco Torres, Juan Pablo

2008 "Música patriótica en la Catedral de Jaén: Compendio sucinto de la revolución española, una obra sobre la Guerra de la Independencia Española (1808-1814)”, Giennium, 11, pp. 323-364.

2010 “El Compendio sucinto de la revolución española (1815) de Ramón Garay (1761-1823)”, Cuadernos de Arte de la Universidad de Granada, 41, pp. 189-212.

Palacios Fernández, Emilio

2008 "Las nuevas formas del teatro breve dieciochesco". Historia del teatro breve en España. Javier Huerta Calvo, director. Madrid: Iberoamericana y Vervuert, pp. 565-584.

Raffi-Béroud, Catherine

1998 En torno al teatro de Fernández de Lizardi. Ámsterdam: Editions Rodopi.

Real Academia de Bellas Artes de San Fernando

[1805] Distribución de los premios concedidos por el Rey Nuestro Señor a los discípulos de las tres nobles artes, hechas por la Real Academia de San Fernando en la Junta pública de 27 de julio de 1805. Madrid: Imprenta de la Hija de Ibarra. Disponible en https://babel.hathitrust.org/cgi/pt?id=ucm $.5326808542 ;$ view=1up;seq=1 [último acceso: 3 de junio de 2019]

Reyes Palacios, Felipe

2004 "Fernández de Lizardi y la comedia lacrimosa". Actas del XIV Congreso de la Asociación Internacional de Hispanistas (Nueva York, 16-21 de julio de 2001) . 4 vols. Isaías Lerner, Roberto Nival y Alejandro Alonso, editores. Newark, Del.: Juan de la Cuesta, vol. 4, pp. 581-588. 
Rípodas Ardanaz, Daisy

1986 "Influencia del teatro menor español del Setecientos sobre la imagen peninsular del indiano". El indiano en el teatro menor español del Setecientos. Daisy Rípodas Ardanaz, editora. Madrid: Ediciones Atlas, pp. I-LVXXIII.

SÁNChEz López, ViRginia

2012 "España de la guerra (1808): la difusión internacional del cancionero de la Guerra de la Independencia", Cuadernos de música iberoamericana, 23, pp. 23-43.

2014 Música, prensa y sociedad en la provincia de Jaén durante el siglo XIX. 2 vols. Jaén: Instituto de Estudios Giennenses, Diputación Provincial de Jaén.

Scarton, Cesare

1998 Il melologo: una ricerca storica tra recitazione e musica. Castello: Edimond.

SChWARZ-Danuser, Monika

1996 "Melodram", Die Musik in Geschichte und Gegenwart. 29 vols. Ludwig Finscher, editor. Kassel: Bärenreiter y Metzler, Sachteil, vol. 6, pp. 67-99.

SHEPHERD, JoHN

2003 "Music and social categories". The cultural study of music. A critical introduction. Martin Clayton, Trevor Herbert y Richard Middleton, editores. Nueva York y Londres: Routledge, pp. 69-79.

Sú́rez-Pajares, Javier

2000 "Melólogo". Diccionario de la música española e hispanoamericana. 10 vols. Emilio Casares Rodicio, director. Madrid: SGAE, vol. 7, pp. 420-421.

Subirá, José

1927 La música en la Casa de Alba: estudios históricos y biográficos. Madrid: Establecimiento Tipográfico Sucesores de Rivadeneyra.

1928 "Los “melólogos" de Rousseau, Iriarte y otros autores", Revista de la Biblioteca, Archivo y Museo de Madrid, 2, pp. 140-161.

1949-1950 El compositor Iriarte y el cultivo español del melólogo (melodrama). 2 vols. Barcelona: Consejo Superior de Investigaciones Científicas.

1953 Un vate filarmónico: Don Luciano Comella. Discurso leído el día 22 de marzo de 1953, en su recepción pública, por el académico electo. Madrid: Real Academia de Bellas Artes de San Fernando.

Sustaeta Llombart, Ignacio

1993 "La música en las fuentes hemerográficas del XVIII español: referencias musicales en la Gaceta de Madrid y artículos de música en los papeles periódicos madrileños”. Tesis doctoral inédita. Universidad Complutense de Madrid. Profesor guía: Emilio Casares.

Tello, Aurelio

2010 "El tránsito de los virreinatos a los estados independientes". Historia de la música en España e Hispanoamérica. Vol. 6: La música en Hispanoamérica en el siglo XIX. Consuelo Carredano y Victoria Eli, editoras (Juan Ángel Vela del Campo, director y coordinador editorial). Madrid: Fondo de Cultura Económica de España, pp. 23-70.

Toral y Fernández de Peñaranda, Enrique

1977 "La concesión del Marquesado del Cerro de la Cabeza", Boletín del Instituto de Estudios Giennenses, 93, pp. 9-52.

Torres Laguna, Carlos de

1981 Andújar a través de sus actas capitulares (1600-1850). Historia de la Ciudad de Andújar y de su Patrona la Virgen de la Cabeza, libro V. Jaén: Instituto de Estudios Giennenses, Diputación Provincial de Jaén. 
Torres Martínez, José Carlos

2010 "El mayorazgo fundado por Cristóbal de Piédrola y su mujer Isabel Palomino de Arjona (1525)". Boletín del Instituto de Estudios Giennenses, 202, pp. 137-204.

WAEBER, JACQUELINE

2005 En musique dans le texte: le mélodrame de Rousseau à Schoenberg. París: Van Dieren.

Periódicos y revistas

Diario Balear, $\mathrm{N}^{\circ} 278$ (17 de abril, 1817); No 87 (26 de junio, 1834); No 52 (21 de agosto, 1835).

Diario de Madrid, $\mathrm{N}^{\circ} 262$ (19 de septiembre, 1793); $\mathrm{N}^{\circ} 239$ (27 de agosto, 1798); $\mathrm{N}^{\circ} 240$ (28 de agosto, 1798 ); $\mathrm{N}^{\circ} 242$ (30 de agosto, 1798); $\mathrm{N}^{\circ} 244$ (1 de septiembre, 1798); $\mathrm{N}^{\circ} 245$ (2 de septiembre, 1798); $\mathrm{N}^{\circ} 257$ (14 de septiembre, 1798); $\mathrm{N}^{\circ} 237$ (25 de agosto, 1800); $\mathrm{N}^{\circ} 9$ (9 de enero, 1801 ); $\mathrm{N}^{\circ} 132$ (12 de mayo, 1802); $\mathrm{N}^{\circ} 133$ (13 de mayo, 1802); $\mathrm{N}^{\circ} 134$ (14 de mayo, 1802); $\mathrm{N}^{\circ} 135$ (15 de mayo, 1802); $\mathrm{N}^{\circ} 136$ (16 de mayo, 1802); $\mathrm{N}^{\circ} 313$ (9 de noviembre, 1809); $\mathrm{N}^{\circ} 33$ (2 de febrero, 1811).

Diario de México, $\mathrm{N}^{\circ} 63$ (2 de diciembre, 1805).

Diario de Palma, $\mathrm{N}^{\circ} 101$ (10 de abril, 1812).

Gazeta de Madrid, $\mathrm{N}^{\circ} 96$ (1 de diciembre, 1797).

El Conciso, $\mathrm{N}^{\circ} 30$ (30 de junio, 1813).

El Español, $\mathrm{N}^{\circ} 527$ (12 de abril, 1837).

El Universal observador español, $\mathrm{N}^{\circ} 19$ (30 de mayo, 1820).

Discografía

Ramón Garay. Las 10 sinfonías. Orquesta de Córdoba, dir. José Luis Temes. 3 CDs. Madrid: Verso VRS2099, 2010.

Archivos y fuentes documentales consultadas

1. Archivo Histórico Diocesano de Jaén (AHDJ)

AHDJ, Archivo Capitular, Sección V, Carpeta de músicos.

AHDJ, Archivo Musical, 40/2 y 42/3, partitura musical, manuscrito.

2. Archivo Histórico de Protocolos de Madrid (AHPM)

AHPM, protocolo 23926, fol. 577, 21 de noviembre de 1836.

3. Archivo Histórico Nacional de Madrid (AHNM)

AHNM, Consejos, 5240, exp. 6, 21 de junio, 1781.

AHNM, Consejos, 11988, exp. 28, 9 de octubre, 1809.

4. Biblioteca Histórica Municipal de Madrid (BHM)

BHM, C-18860-5, libreto literario, impreso. 
BHM, Mus. 22-20, partitura musical, manuscrito.

BHM, Tea 1-50-5, A, libreto literario, manuscrito.

BHM, Tea 1-50-5, a1, libreto literario, impreso.

BHM, Tea 1-50-5, a2, libreto literario, impreso.

BHM, Tea 1-50-5, B, libreto literario, manuscrito.

BHM, Tea 1-50-5, C, libreto literario, manuscrito.

BHM, Tea 1-50-5, C, libreto literario, manuscrito.

\section{Biblioteca Nacional de la República Argentina, Buenos Aires (BNRA)}

BNRA, núm. 14.759, tomo 7.

6. Instituto de Estudios Giennenses, Jaén (IEG)

IEG, Fotografías en papel, A-284-7/1.

7. Yale University Library (YUL)

YUL, Beinecke Rare Book and Manuscript Library, Mexico He93m 343.

\section{Catálogos en línea}

- Biblioteca Histórica Municipal de Madrid (http://catalogos.munimadrid.es/cgi-bin/ historica)

- Biblioteca Nacional de la República Argentina (https://www.bn.gov.ar)

- $\quad$ Biblioteca Virtual Miguel de Cervantes (http://www.cervantesvirtual.com)

- Hemeroteca Digital. Biblioteca Nacional de España (http://www.bne.es/es/Catalogos/ HemerotecaDigital/)

- WorldCat. Online Computer Library Center (https://www.worldcat.org) 


\section{ANEXOS}

Anexo 1. Apuntes de El negro sensible en la Biblioteca Histórica Municipal de Madrid ${ }^{82}$

\begin{tabular}{|c|c|l|}
\hline Apunte & Signatura & \multicolumn{1}{c|}{ Observaciones } \\
\hline $1^{\circ}$ & Tea 1-50-5, B & $\begin{array}{l}\text { Cuaderno manuscrito, 14 fols. numerados. Incluye el texto } \\
\text { dramático, el elenco de personajes y el reparto: Catul negro: } \\
\text { Manuel García [Parra]; Jacobo: [José] Huerta; Doña Martina: } \\
\text { Señora Vázquez; Don Vicente: [Agustín] Roldán; Juanito chico: } \\
\text { Señora Laureana [Correa]; una criada: Señora [Josefa] Virg; un } \\
\text { negrito, no habla. La copia incluye anotaciones acerca de las } \\
\text { entradas musicales y, ocasionalmente, de algún personaje. Al final } \\
\text { se escribió: "Finis coronat opus". }\end{array}$ \\
\hline $2^{\circ}$ & Tea 1-50-5, A & $\begin{array}{l}\text { Cuaderno manuscrito, 12 fols. numerados. Incluye el texto } \\
\text { dramático, el elenco de personajes (aunque no el de los actores) } \\
\text { y unas pocas anotaciones con la entrada del actor Roldán (Don } \\
\text { Vicente). }\end{array}$ \\
\hline $3^{\circ}$ & Tea 1-50-5, C & $\begin{array}{l}\text { Cuaderno manuscrito, 16 fols. sin numerar. Junto con la } \\
\text { información contenida en la portada de los dos anteriores } \\
\text { apuntes (título, género y números de actos), la de este incluye } \\
\text { información detallada de los intérpretes ("Para las 2 compañías } \\
\text { de Madrid"), el autor del texto ("D" Luciano Franco. Comella") } \\
\text { y la fecha ("Año de 1798"). Repite los nombres de los actores del } \\
\text { apunte 1 e incluye numerosos tachones y anotaciones referidas } \\
\text { a números musicales, efectos de luz, movimientos y espacio. Los } \\
\text { dos últimos folios incluyen la licencia de representación, firmada } \\
\text { por Morales y fechada el 23 de agosto de 1798 (ver Figura 1). }\end{array}$ \\
\hline $1^{\circ}$ & $\begin{array}{l}\text { Tuaderno impreso (Salamanca, Imprenta de Francisco de Tóxar, } \\
\text { in fecha), 8 pp. numeradas + portada manuscrita. Una anotación } \\
\text { manuscrita en la p. 1 del impreso indica "pa la Cruz". El ejemplar } \\
\text { incluye anotaciones manuscritas con indicaciones de las entradas } \\
\text { musicales, ocasionales efectos de luz y correcciones de algunas } \\
\text { frases. En la p. 8 bajo el pie de imprenta se escribió "Aprobada } \\
\text { Madrid 3 Noviembre 1809. Arribas [rúbrica]". }\end{array}$ \\
\hline
\end{tabular}

82 Catálogo en línea de la Biblioteca Histórica Municipal, accesible en http://catalogos.munimadrid.es/cgi-bin/historica/O7075/ID3f9d5a37/NT2. 


\begin{tabular}{|c|c|l|}
\hline Apunte & Signatura & \multicolumn{1}{c|}{ Observaciones } \\
\hline $1^{\circ}$ & Tea 1-50-5, a2 & $\begin{array}{l}\text { Se trata de otro ejemplar de la misma edición, precedido de una } \\
\text { portada manuscrita. El libreto incorpora anotaciones manuscritas } \\
\text { con las participaciones musicales y la entrada de los actores, cuyo } \\
\text { elenco se especifica al reverso de la portada manuscrita que } \\
\text { antecede el impreso: Catul: Eugenio; Jacobo: } 2^{\circ} ; D^{a} \text { Martina: } \\
\text { Coleta; Niño [en blanco]; Inés: Galindo; Don Vicente: Ribera; } \\
\text { Niño negro [en blanco]. }\end{array}$ \\
\hline C-18860-5 & $\begin{array}{l}\text { Cuaderno impreso ([Madrid], Librería de la viuda de Quiroga, } \\
\text { calle de las Carretas, núm. 9, sin año [¿1798?; el catálogo onlinela } \\
\text { fecha “[post. 1804]"), 8 pp. numeradas. No contiene anotaciones } \\
\text { manuscritas. }\end{array}$ \\
\hline
\end{tabular}

Anexo 2. Comparativa de las acotaciones escénicas de El negro sensible en las versiones de Madrid y Jaén

\begin{tabular}{|l|l|}
\hline \multicolumn{1}{|c|}{$\begin{array}{l}\text { Acotación escénica del libreto impreso } \\
\text { (Madrid, BHM, C-18860-5) }\end{array}$} & $\begin{array}{l}\text { Acotación escénica de la partitura de Garay } \\
\text { (Jaén, AHDJ, 40/2) }\end{array}$ \\
\hline $\begin{array}{l}{[\mathrm{I}]} \\
{[\text { Catul] Se abraza con el niño; música }} \\
\text { patética, que de pronto pasa a un piano que } \\
\text { anuncia la venida del nuevo sol y el canto de } \\
\text { las aves; pasa el sol y aclarece el teatro. }\end{array}$ & $\begin{array}{l}{[\mathrm{I}]} \\
\text { Catul se abraza con el niño. } \\
\text { Respuesta: Ya parece que en brazos \& }{ }^{\mathrm{a}} \text {. } \\
\text { al trabajo. } \\
\text { muy temprano \&a } \\
\text { al descanso. } \\
\text { mas que miro!, y sigue solo. }\end{array}$ \\
& $\begin{array}{l}\text { Esta escena se representará como va anotada, } \\
\text { y si acaso le faltare algo que hablar a Catul } \\
\text { cuando llegue al calderón (que lo deberá } \\
\text { medir de modo que le falte), callará la música, } \\
\text { y luego que concluya, dirá el violín primero el } \\
\text { compás de música que tiene a solo, y volverá } \\
\text { a representar los dos versos siguientes muy } \\
\text { despacio alargando, entreteniéndose con el } \\
\text { niño. }\end{array}$ \\
\hline $\begin{array}{l}\text { Sale Jacobo de la puerta, despierta a los } \\
\text { negros con un látigo, los que se dispondrán } \\
\text { para el trabajo; Catul coge frutas de los } \\
\text { árboles; tres de los negros se van al ingenio; y } \\
\text { los otros se van de la escena. }\end{array}$ & \\
\hline
\end{tabular}




\begin{tabular}{|c|c|}
\hline $\begin{array}{l}\text { Acotación escénica del libreto impreso } \\
\text { (Madrid, BHM, C-18860-5) }\end{array}$ & $\begin{array}{c}\text { Acotación escénica de la partitura de Garay } \\
\text { (Jaén, AHDJ, 40/2) }\end{array}$ \\
\hline $\begin{array}{l}\text { [III] } \\
\text { Música: [Catul] Se estrecha tiernamente con } \\
\text { el hijo, después besa los pies a Jacobo y se va. }\end{array}$ & $\begin{array}{l}{[\mathrm{II}]} \\
\text { Catul se estrecha tiernamente con su hijo. } \\
\text { Toda esta música se ejecutará entre tanto que } \\
\text { Catul se estrecha tiernamente con su hijo, } \\
\text { besa los pies a Jacobo y se va. }\end{array}$ \\
\hline $\begin{array}{l}\text { [IV] } \\
\text { Jacobo llega a recibir a Doña Martina, que } \\
\text { saldrá acompañada por Don Vicente, su } \\
\text { mayordomo, que traerá de la mano a Juanito, } \\
\text { y criadas: se saludan mutuamente, le dan } \\
\text { a entender a Jacobo cómo vienen a ver el } \\
\text { ingenio, y él pasa a enseñarlo, mandando a } \\
\text { los negros dejen de trabajar; estos y los que } \\
\text { habrán salido se ponen en fila; el negrito, } \\
\text { así que los ve, se admira, hace que quiere ir } \\
\text { a ver el otro niño, pero se detiene. Toda esta } \\
\text { escena la expresará la música. }\end{array}$ & $\begin{array}{l}{[\mathrm{III}]} \\
\text { Toda esta escena se ejecutará sin que hay } \\
\text { representación en nada de ella. }\end{array}$ \\
\hline $\begin{array}{l}\text { [V] } \\
\text { Música: Los negros se postran a Doña } \\
\text { Martina; les reparte el dinero; distraídas las } \\
\text { dos criadas en ver el ingenio, no reparan que } \\
\text { Juanito se ha ido con el negrito, el que le } \\
\text { regala las frutas. }\end{array}$ & $\begin{array}{l}{[\mathrm{IV}]} \\
\text { Los negros se postran a Doña Martina. } \\
\text { Doña Martina los consuela, alegre y les } \\
\text { reparte dinero. } \\
\text { Distracción de las criadas. } \\
\text { Regalo de frutas } \\
\text { Esta es una de las escenas más interesantes y la } \\
\text { que sigue también hará buen efecto. }\end{array}$ \\
\hline $\begin{array}{l}{[\mathrm{VI}]} \\
\text { Música: Sale Catul con un haz de cañas al } \\
\text { hombro, de cuyo peso vendrá agobiado; lo } \\
\text { pone en el suelo, se sienta sobre él y después } \\
\text { de tomar un poco de aliento dice. }\end{array}$ & $\begin{array}{l}{[\mathrm{V}]} \\
\text { Catul sale con un haz de cañas al hombro } \&^{\mathrm{a}} \text {. } \\
\text { Se sienta y descansa. } \\
\text { Después de tomar un poco de aliento } \&^{\mathrm{a}} \text {. } \\
\text { Representa. }\end{array}$ \\
\hline $\begin{array}{l}\text { [VII] } \\
\text { Jacobo cierra la puerta de pronto, Catul se va } \\
\text { tras de él, y al tiempo de llegar a la puerta cae } \\
\text { desmayado: Música: a este tiempo salen por } \\
\text { el foro Doña Martina, Juanito e Inés criada. }\end{array}$ & $\begin{array}{l}{[\mathrm{VI}]} \\
\text { Jacobo cierra la puerta prontamente. } \\
\text { Catul va tras de él. } \\
\text { Desmayo de Catul al llegar a la puerta. } \\
\text { Salida de Doña Martina, Juanito, \& } \&^{\mathrm{a}} \text {. } \\
\text { Sigue otra. }\end{array}$ \\
\hline $\begin{array}{l}{[\mathrm{VIII}]} \\
\text { Música: Catul se queda muy pensativo. }\end{array}$ & $\begin{array}{l}{[\mathrm{VII}]} \\
\text { Catul se queda muy pensativo. }\end{array}$ \\
\hline
\end{tabular}




\begin{tabular}{|l|l|}
\hline \multicolumn{1}{|c|}{$\begin{array}{c}\text { Acotación escénica del libreto impreso } \\
\text { (Madrid, BHM, C-18860-5) }\end{array}$} & $\begin{array}{l}\text { Acotación escénica de la partitura de Garay } \\
\text { (Jaén, AHDJ, 40/2) }\end{array}$ \\
\hline $\begin{array}{l}{[\mathrm{IX}]} \\
\text { El negrito trae de la mano a Doña Martina, } \\
\text { la lleva a la choza, después hacia el ingenio, y } \\
\text { viendo que no encuentra a su padre, llora. }\end{array}$ & $\begin{array}{l}\text { [VIII] } \\
\text { El negrito trae de la mano a Doña Martina. } \\
\text { La lleva a la choza. } \\
\text { Después hacia el ingenio. } \\
\text { Lloro del negrito porque no encuentra a su } \\
\text { padre. }\end{array}$ \\
\hline $\begin{array}{l}\text { Un }] \\
\text { del pueño; vuelve a leer, pero insensiblemente } \\
\text { se queda dormida; Catul la observa. }\end{array}$ & \\
\hline $\begin{array}{l}\text { [XI }] \\
\text { Catul se abraza al niño; Doña Martina habla } \\
\text { con Don Vicente que habrá salido con las } \\
\text { criadas y Juanito; Catul de pronto se levante } \\
\text { y se postra a los pies de Doña Martina; Don } \\
\text { Vicente se va apresurado en casa de Jacobo, } \\
\text { el que sale, y se entran. }\end{array}$ & \\
\hline
\end{tabular}

